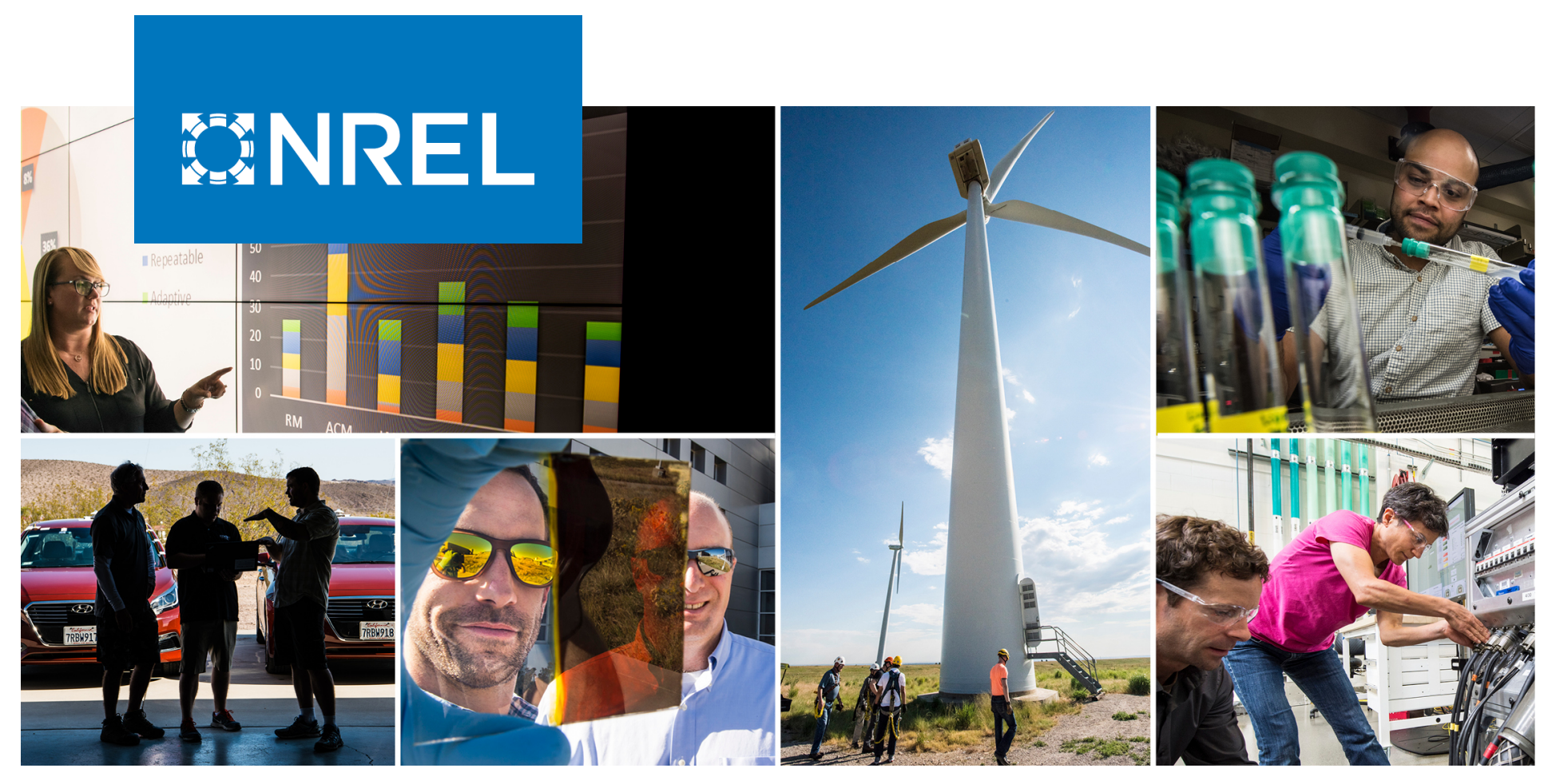

\title{
Quantifying the Solar Energy Resource for Puerto Rico
}

Nick Grue, Grant Buster, Andrew Kumler, Yu Xie, Manajit Sengupta, and Murali Baggu

National Renewable Energy Laboratory

NREL is a national laboratory of the U.S. Department of Energy Office of Energy Efficiency \& Renewable Energy

Operated by the Alliance for Sustainable Energy, LLC

This report is available at no cost from the National Renewable Energy Laboratory (NREL) at www.nrel.gov/publications.

\section{Technical Report}

NREL/TP-5D00-75524

May 2021 


\title{
GNREL
}

\section{Quantifying the Solar Energy Resource for Puerto Rico}

\author{
Nick Grue, Grant Buster, Andrew Kumler, Yu Xie, \\ Manajit Sengupta, and Murali Baggu \\ National Renewable Energy Laboratory
}

\section{Suggested Citation}

Grue, Nick, Grant Buster, Andrew Kumler, Yu Xie, Manajit Sengupta, and Murali Baggu. 2021. Quantifying the Solar Energy Resource for Puerto Rico. Golden, CO: National Renewable Energy Laboratory. NREL/TP-5D00-75524.

https://www.nrel.gov/docs/fy210sti/75524.pdf.

NREL is a national laboratory of the U.S. Department of Energy Office of Energy Efficiency \& Renewable Energy Operated by the Alliance for Sustainable Energy, LLC

This report is available at no cost from the National Renewable Energy Laboratory (NREL) at www.nrel.gov/publications.

Contract No. DE-AC36-08GO28308
Technical Report NREL/TP-5D00-75524 May 2021

National Renewable Energy Laboratory 15013 Denver West Parkway Golden, CO 80401 303-275-3000 • www.nrel.gov 


\section{NOTICE}

This work was authored by the National Renewable Energy Laboratory, operated by Alliance for Sustainable Energy, LLC, for the U.S. Department of Energy (DOE) under Contract No. DE-AC36-08GO28308. Funding provided by the U.S. Department of Energy Office of Energy Efficiency and Renewable Energy Solar Energy Technologies Office and Office of Electricity. The views expressed herein do not necessarily represent the views of the DOE or the U.S. Government.

This report is available at no cost from the National Renewable Energy Laboratory (NREL) at www.nrel.gov/publications.

U.S. Department of Energy (DOE) reports produced after 1991 and a growing number of pre-1991 documents are available free via www.OSTI.gov.

Cover Photos by Dennis Schroeder: (clockwise, left to right) NREL 51934, NREL 45897, NREL 42160, NREL 45891, NREL 48097, NREL 46526.

NREL prints on paper that contains recycled content. 


\section{Acknowledgments}

This work was authored by the National Renewable Energy Laboratory, operated by Alliance for Sustainable Energy, LLC, for the U.S. Department of Energy (DOE) under Contract No. DEAC36-08GO28308. Funding and support provided by U.S. Department of Energy Office of Energy Efficiency and Renewable Energy Solar Energy Technologies Office and Office of Electricity. The views expressed herein do not necessarily represent the views of the DOE or the U.S. Government. 


\section{List of Acronyms}

$\mathrm{COV}$

DISC

DNI

FARMS

GHI

IDW

LCOE

MBE

MERRA-2

NREL

NSRDB

PSM

RMSE

SAM

SURFRAD coefficient of variation

Direct Insolation Simulation Code

direct normal irradiance

Fast All-Sky Radiation Model for Solar Applications

global horizontal irradiance

inverse distance weighted

levelized cost of energy

mean bias error

Modern-Era Retrospective Analysis for Research and Applications,

Version 2

National Renewable Energy Laboratory

National Solar Radiation Database

Physical Solar Model

root mean square error

System Advisor Model

Surface Radiation Budget Network 


\section{Executive Summary}

After Hurricane Maria, multiple U.S. Department of Energy laboratories studied the state of the electric grid in Puerto Rico and analyzed grid resilience and grid integration of renewable energy. As part of the work done at the National Renewable Energy Laboratory, researchers created new solar resource data, conducted a technical potential and supply curve analysis, and studied the interannual variability of the solar resource.

A new methodology was developed to downscale solar resource data from the National Solar Radiation Database (NSRDB) from a 4-km x 4-km spatial and 30-minute temporal resolution to a $2 \mathrm{~km} \times 2 \mathrm{~km}$ and 5-minute resolution. This methodology primarily used simple physical principles to develop high-resolution cloud properties that were then used to compute solar radiation. The high-resolution data sets were validated against ground measurements, and the error metrics were found to be similar to the original lower resolution data set.

Using 20 years of downscaled data from the NSRDB (1998-2017), multiyear capacity factors for photovoltaics (PV) were developed for both single-axis tracking and fixed latitude-tilt configurations. Use of the multiyear data provides the ability to understand variability in capacity factors as a result of variability in weather during a long period of time. For Puerto Rico, the coastal regions were found to have significantly higher capacity factors than inland.

Using land-use and terrain information, a technical potential analysis for utility-scale PV plants was conducted for Puerto Rico. This analysis restricted single modeled PV plant development to a maximum nameplate capacity of $100 \mathrm{MW}$. The nameplate capacities for each municipality were then determined. Based on our assumptions, 56 of the 78 total municipalities of Puerto Rico contain some level of solar capacity. Most interior municipalities did not have any capacity because of the geographic exclusions used in this study. The lowest capacity for a single modeled PV plant allowed was $10 \mathrm{MW}$. The maximum total PV capacity within a county was 2,000 MW.

Further, a supply curve analysis was conducted by taking the results of the technical potential and quantifying system and transmission costs. The levelized cost of energy (LCOE) was calculated for each theoretical PV plant site, and the levelized cost of transmission was added to the LCOE to produce a total cost estimate for each site. The results of the supply curve analysis allow for a relative comparison of the cost for integrating new PV capacity into the grid. This analysis indicates that cheaper total LCOE sites tend to be larger in capacity. The total capacity in this study was found to far exceed the maximum peak load for the island; however, this study does not consider the economic and market potential for development. The cumulative capacity presented in this study assumes that the best locations are developed first, and it ignores the complex decision paths for new power plant development; therefore, this analysis can be treated only as illustrative.

Finally, this study investigates the impact of interannual variability of the resource using a variety of metrics, including the probability of exceedance and variation in capacity factor and LCOE. This study demonstrates that the capacity factor or LCOE could vary by more than $10 \%$ from one year to another. This clearly indicates the risks involved in using any particular year of 
data and clearly points to the use of multiyear data to reduce some of the risks related to variability in weather. 


\section{Table of Contents}

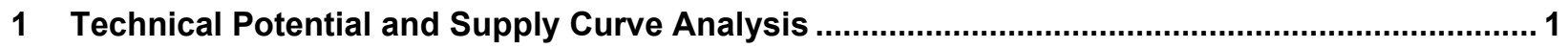

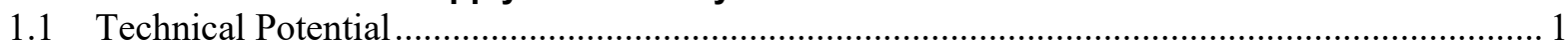

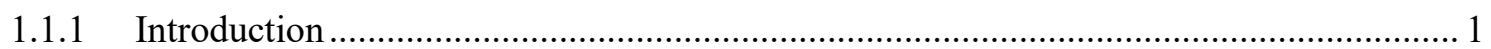

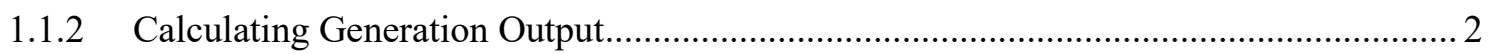

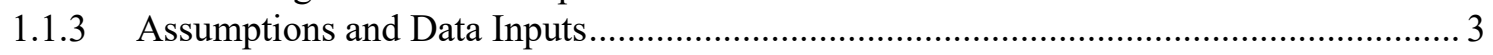

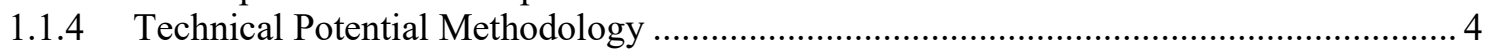

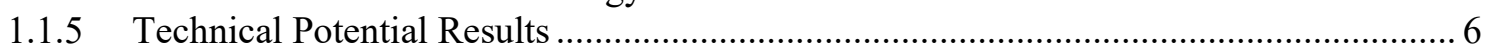

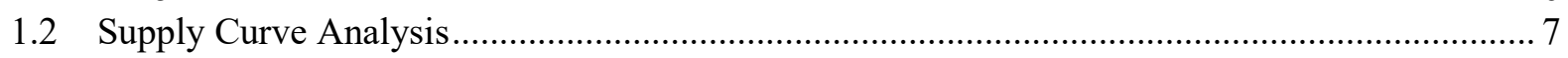

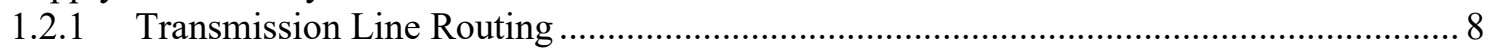

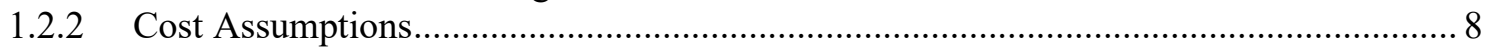

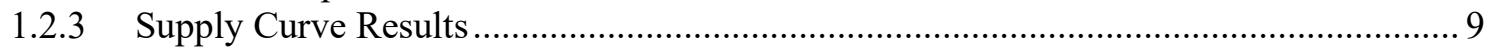

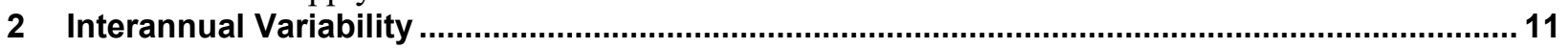

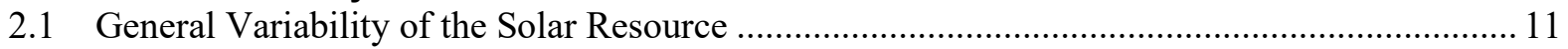

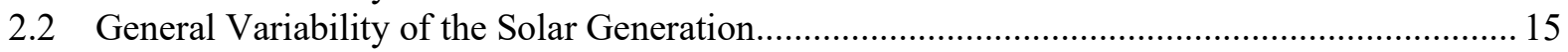

2.3 General Variability of the Levelized Cost of Energy ........................................................... 20

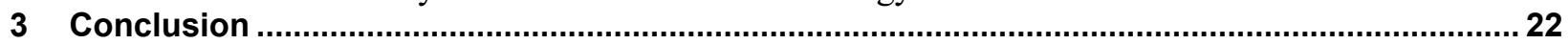

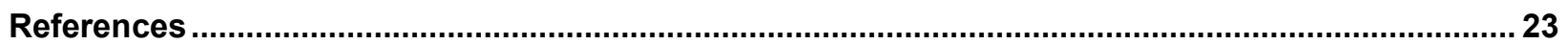




\section{List of Figures}

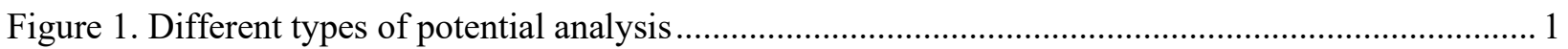

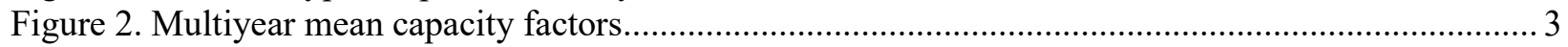

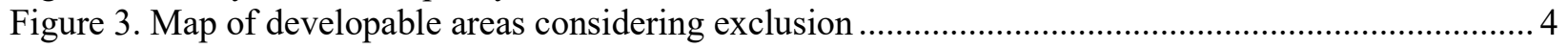

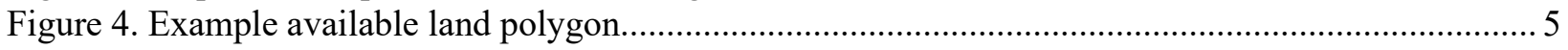

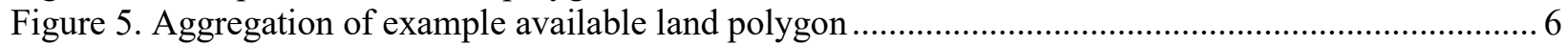

Figure 6. Technical Potential PV capacity for Puerto Rico ............................................................. 7

Figure 7. Technical Potential Mean PV generation per year by municipality ....................................... 7

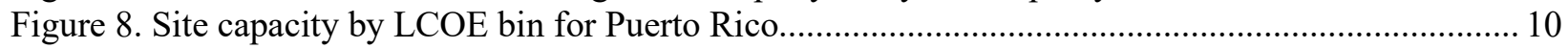

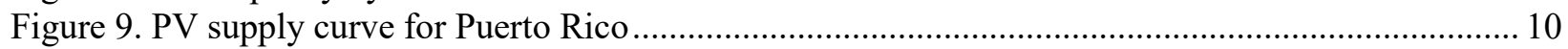

Figure 10. Interannual variability of GHI for Puerto Rico from 1998-2017 shown on the monthly scale.

The blue line and dots represent the mean for those months, and the box plot represents the monthly ranges during the 20 years.

Figure 11. Interannual variability of DNI for Puerto Rico from 1998-2017 shown on the monthly scale. The blue line and dots represent the mean for those months, and the box plot represents the monthly ranges during the 20 years.

Figure 12. Interannual variability of GHI for Puerto Rico from 1998-2017. The blue line and dots represent the mean for those months, and the box plot represents the monthly ranges during

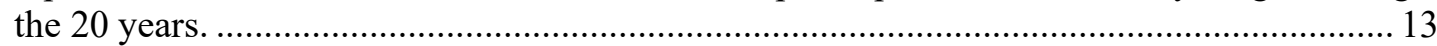

Figure 13. Annual average GHI for Puerto Rico ................................................................................. 14

Figure 14. Variability of GHI in terms of COV. Generally, there is more variability in the mountainous

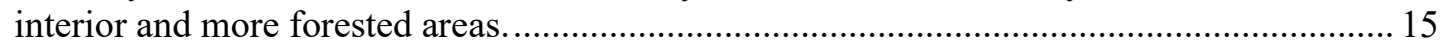

Figure 15. Interannual variability of (a) fixed-tilt solar generation and (b) 1-axis solar generation. Box plots are based on monthly averages for each pixel........................................................... 16

Figure 16. P10 exceedance probabilities for fixed-tilt (top) and 1-axis (bottom) tracking setups.............. 17

Figure 17. P50 exceedance probabilities for fixed-tilt (top) and 1-axis (bottom) tracking setups.............. 18

Figure 18. P90 exceedance probabilities for fixed-tilt (top) and 1-axis (bottom) tracking setups............. 19

Figure 19. Interannual variability of LCOE for fixed-tilt PV setups (a) and respective capacity factors (b)

Figure 20. Interannual variability of LCOE for 1-axis tracking setups (a) and respective capacity factors (b)

\section{List of Tables}

Table 1. Modeled PV System Configuration (1-Axis Tracking) ............................................................. 2

Table 2. Modeled PV System Configuration (Fixed Tilt) ................................................................. 3

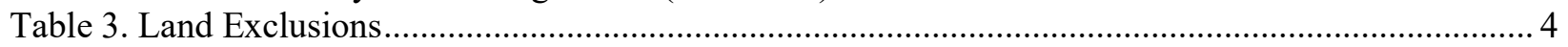

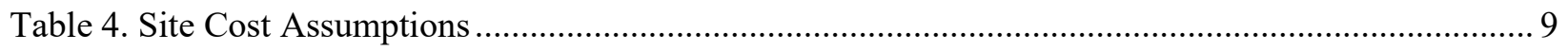

Table 5. Transmission Cost Assumptions ............................................................................................ 9

Table 6. Associated Costs (Capital and Fixed Operation-and-Maintenance) for Fixed-Tilt and 1-Axis Tracking PV Setups in Relation to the LCOE Calculation ................................................ 21 


\section{Technical Potential and Supply Curve Analysis}

To evaluate the available capacity of the solar resource for integration into the grid, analysis that investigates the availability of the land for the development of new solar generation should be conducted. Not all land areas are available for the development of solar generation plants; therefore, a technical potential analysis was conducted to filter out locations that would not be available for development and separate areas of land where solar development is feasible. Once locations are selected as being available for development, the cost of the development and integration of new solar power plants at each location can be calculated. The supply curve analysis evaluates the potential costs for developing a given location and connecting it to the grid.

\subsection{Technical Potential}

\subsubsection{Introduction}

A technical potential analysis establishes an upper boundary estimate of development potential (Lopez et al. 2012). This analysis considers constraints to development, including various land uses and land covers, protected areas, and culturally sensitive locations that would inhibit development. This analysis also considers some technical aspects for development, such as slope, which would affect the cost of new systems and make them less likely for development. It is important to distinguish the differences between a technical potential analysis and other analyses, such as economic potential and market potential (Figure 1).

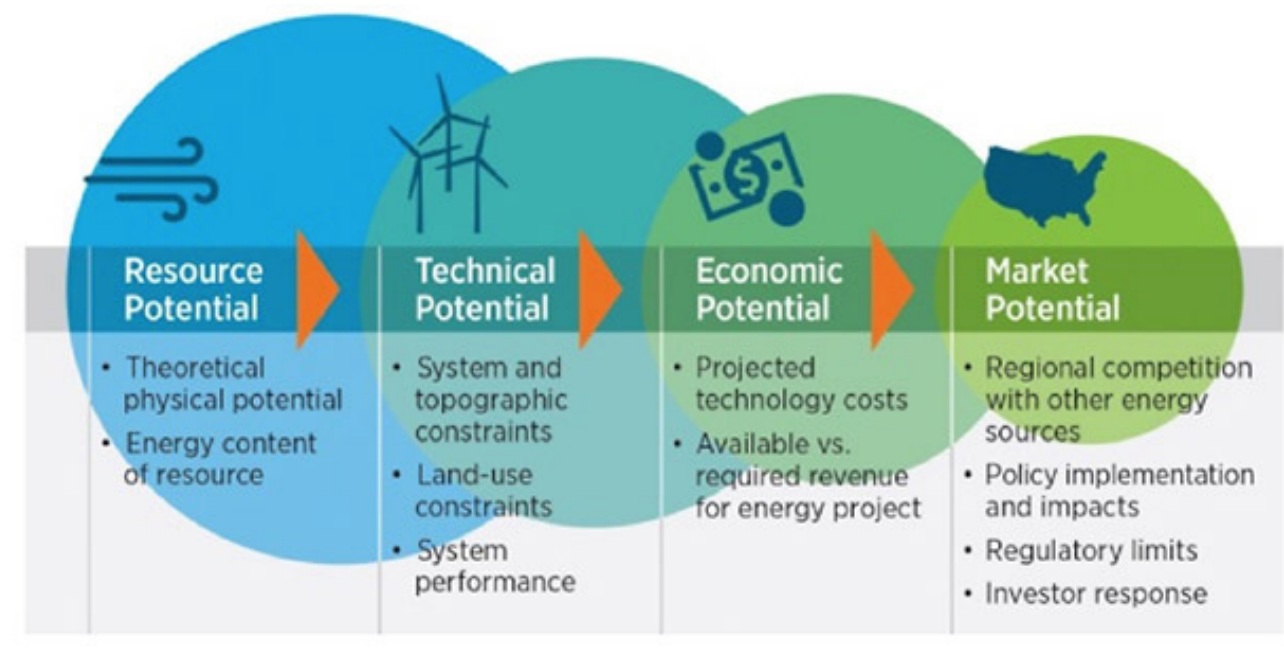

Source: Brown et al. 2016

Figure 1. Different types of potential analysis

Economic potential considers projected technology costs and revenue for electricity generation, which the technical potential does not consider. Market potential draws on additional factors, such as policy and regulation as well as market demand for electricity, which are also not considered in the technical potential. The technical potential analysis quantifies the availability of the resource that can be developed, regardless of demand or system costs. 


\subsubsection{Calculating Generation Output}

To evaluate potential electricity generation output, we used methods developed specifically for this project by Buster et al. (2021) to downscale data from the NSRDB (Sengupta et al. 2018) from the 4-km 30-min native NSRDB resolution to a finer 2-km 5-min resolution. Buster et al. (2021) details additional results of the downscaling methodology including quantitative validation against ground measurement data and qualitative validation against real PV plants in Puerto Rico. We then used The System Advisor Model (SAM, Blair et al. 2017) to calculate potential generation output for a 1-axis tracking PV power system with the downscaled 2-km 5min resolution solar irradiance data as input. SAM was used to calculate potential generation output across all 20 years of available NSRDB data (1998-2017) to give a multiyear mean capacity factor that could inform potential long-term mean generation for every site across Puerto Rico and the U.S. Virgin Islands. It should be noted that since this work was completed, new NSRDB data from 2018 onwards was released with native high-resolution 2-km 5-min data for Puerto Rico and the U.S. Virigin Islands. The availability of new native high resolution data is due to the new generation of GOES satellite that was used to produce NSRDB data starting in 2018. Future revisions of this work may focus on including the new native high-resolution data for more detailed analysis.

The configuration of the generic PV power system is outlined in Table 1.

Table 1. Modeled PV System Configuration (1-Axis Tracking)

\begin{tabular}{|l|l|}
\hline Parameter & Setting \\
\hline Type & 1 -axis tracking \\
\hline Losses & $14.07 \%$ \\
\hline Tilt & 0 degrees \\
\hline Panel type & Standard \\
\hline Inverter efficiency & $96 \%$ \\
\hline Ground cover ratio & 0.4 \\
\hline DC/AC ratio & 1.3 \\
\hline Power density & $32 \mathrm{MW} / \mathrm{km}^{2}$ \\
\hline
\end{tabular}

For the interannual variability study, a similar fixed-tilt solar system was evaluated with the configurations listed in Table 2. 
Table 2. Modeled PV System Configuration (Fixed Tilt)

\begin{tabular}{|l|l|}
\hline Parameter & Setting \\
\hline Type & Fixed tilt \\
\hline Losses & $14.07 \%$ \\
\hline Tilt & 10 degrees \\
\hline Panel type & Standard \\
\hline Inverter efficiency & $96 \%$ \\
\hline Ground cover ratio & 0.4 \\
\hline DC/AC ratio & 1.3 \\
\hline Power density & $32 \mathrm{MW} / \mathrm{km}^{2}$ \\
\hline
\end{tabular}

The resulting long-term mean net capacity factors using the PV system configuration listed in Table 2 and the NSRDB simulated high-resolution data are illustrated in Figure 2.

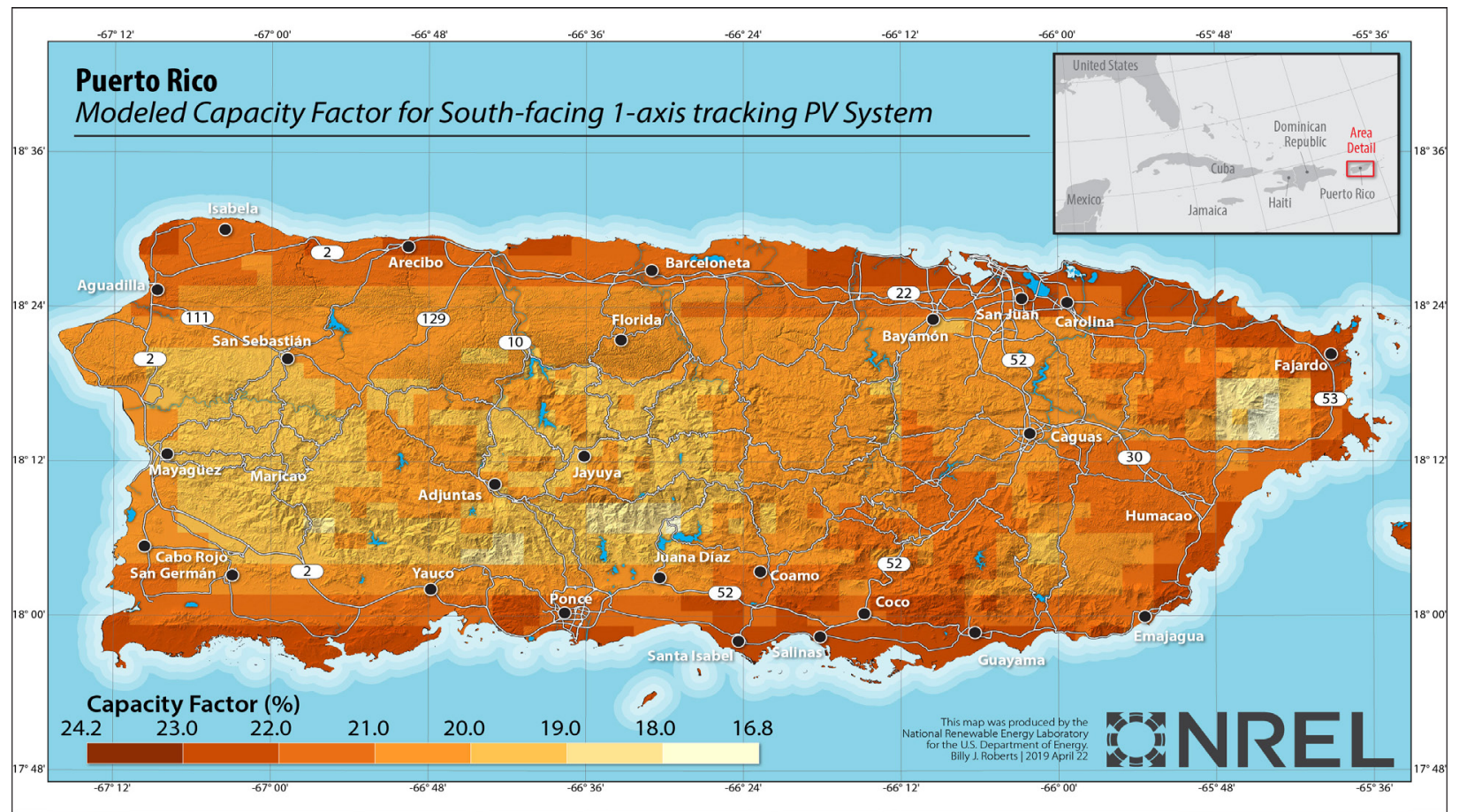

Figure 2. Multiyear mean capacity factors

\subsubsection{Assumptions and Data Inputs}

Spatial data are used for evaluating the availability of areas of land for new renewable energy development within a geographic information system setting. The data sources used for this analysis were a combination of global and local data sets, as shown in the source column of Table 3. 
Table 3. Land Exclusions

\begin{tabular}{|l|l|l|}
\hline Category & Source & Exclusion Arguments \\
\hline Slope & U.S. Forest Service & $>5 \%$ slope \\
\hline Man-made structures & $\begin{array}{l}\text { Humanitarian } \\
\text { OpenStreetMap Team }\end{array}$ & $\begin{array}{l}\text { Presence of man-made } \\
\text { structures }\end{array}$ \\
\hline Protected areas & U.S. Forest Service & Presence of protected areas \\
\hline Land cover & $\begin{array}{l}\text { Multi-Resolution Land } \\
\text { Characteristics Consortium } \\
\text { National Land Cover } \\
\text { Database }(2001)\end{array}$ & $\begin{array}{l}\text { Water bodies, wetlands, } \\
\text { developed land }\end{array}$ \\
\hline Contiguous area filter & $\mathrm{n} / \mathrm{a}$ & $<0.2 \mathrm{~km}^{2}$ \\
\hline
\end{tabular}

After each exclusion shown in Table 3 is applied, the resulting locations on the island are considered available for development (Figure 3). These available locations consider only the exclusions listed and do not consider more nuanced land use categories that would preclude the development of certain sites. As shown in Figure 3, most of the land area is excluded, whereas most of the available areas are located close to the coastal regions.

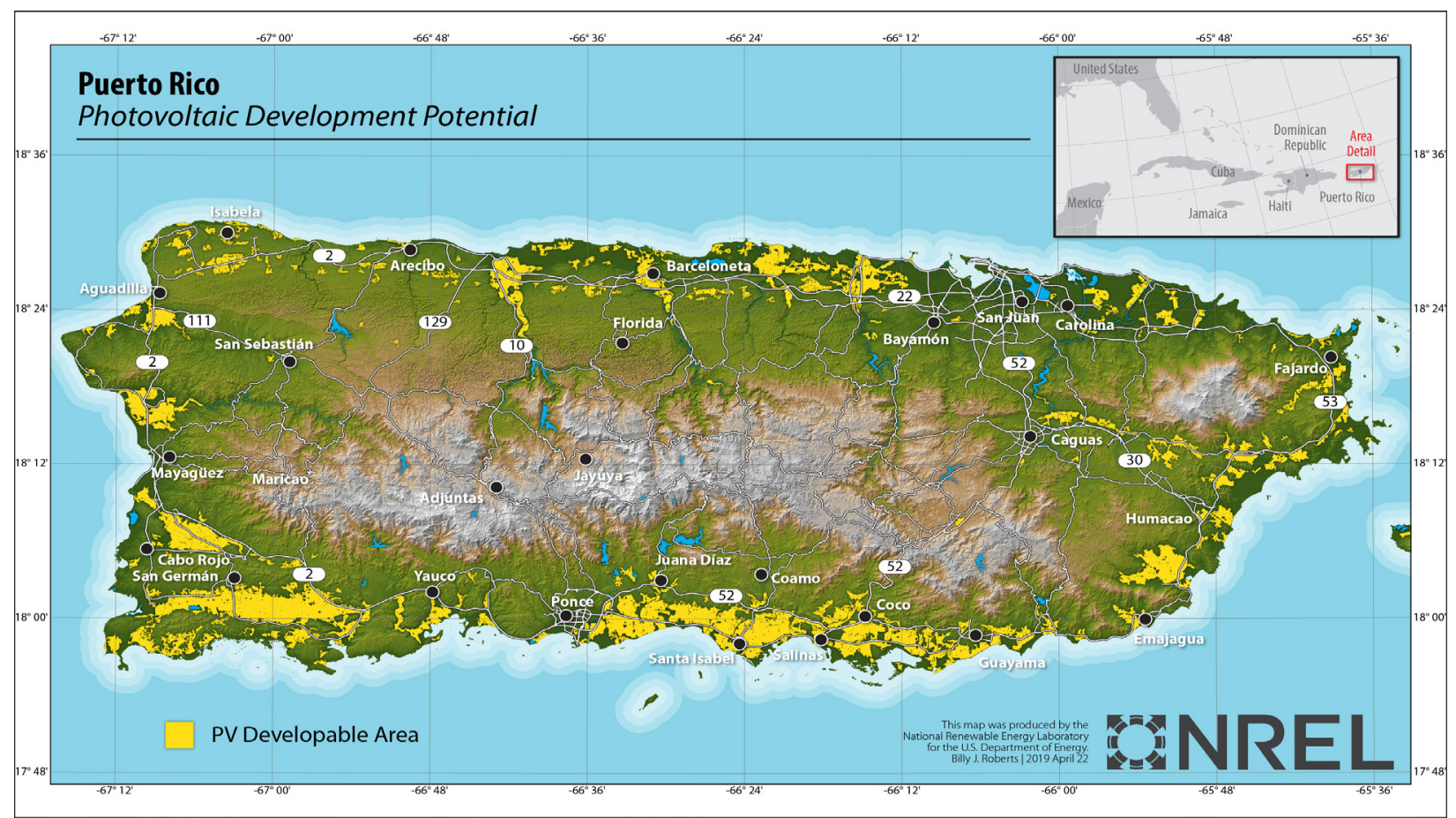

Figure 3. Map of developable areas considering exclusion

\subsubsection{Technical Potential Methodology}

The reduction of land to available areas can produce very large swaths of land that remain developable. To better represent a solar power plant, these swaths of land need to be aggregated into discreet landmasses with limited capacity to avoid creating very large power plants that 
would be difficult to analyze. Aggregating also allows for better calculation of transmission costs because new transmission lines (in this report called "spur lines") need to be routed to a central point for each PV power plant. The following sections describe how the PV plants are characterized and how costs are calculated for each.

\subsubsection{Aggregating Land to Discreet Areas}

Once land for development is identified, the land must be subdivided to better represent a discrete PV power plant. The polygons that represent available land can represent potentially tens of square kilometers of available land (e.g., Figure 4). This represents a challenge for calculating capacity and transmission costs because a central location must be selected to act as the origination point for a new transmission tie-in line (spur line). For a polygon like that shown in Figure 4, the location could span more than $80 \mathrm{~km}^{2}$.

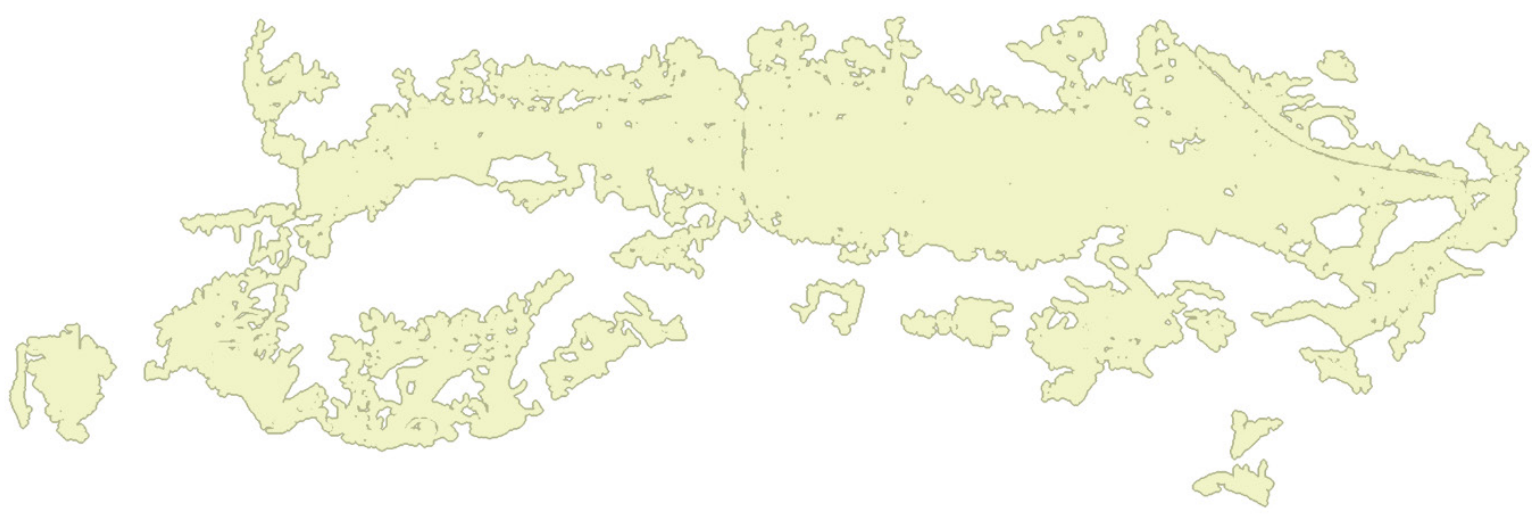

Figure 4. Example available land polygon

To better compare discreet polygons of available land, an additional processing step is conducted to discretize these large areas of land.

Using a semi-random image processing algorithm, the large polygons of land are broken into smaller portions of land and rechecked for available area. The goal of this processing is to produce land area that could support no greater than $100 \mathrm{MW}$. The calculation for converting available land into capacity is described in later sections.

The process to discretize the land areas attempts to create rectangular shapes by splitting polygons into four quadrants. After each split, the resulting polygon area is checked. If the polygon still covers an area greater than $3.125 \mathrm{~km}^{2}$, the polygon is split again. The resulting split of the large polygon example shown in Figure 4 is visualized in Figure 5. 


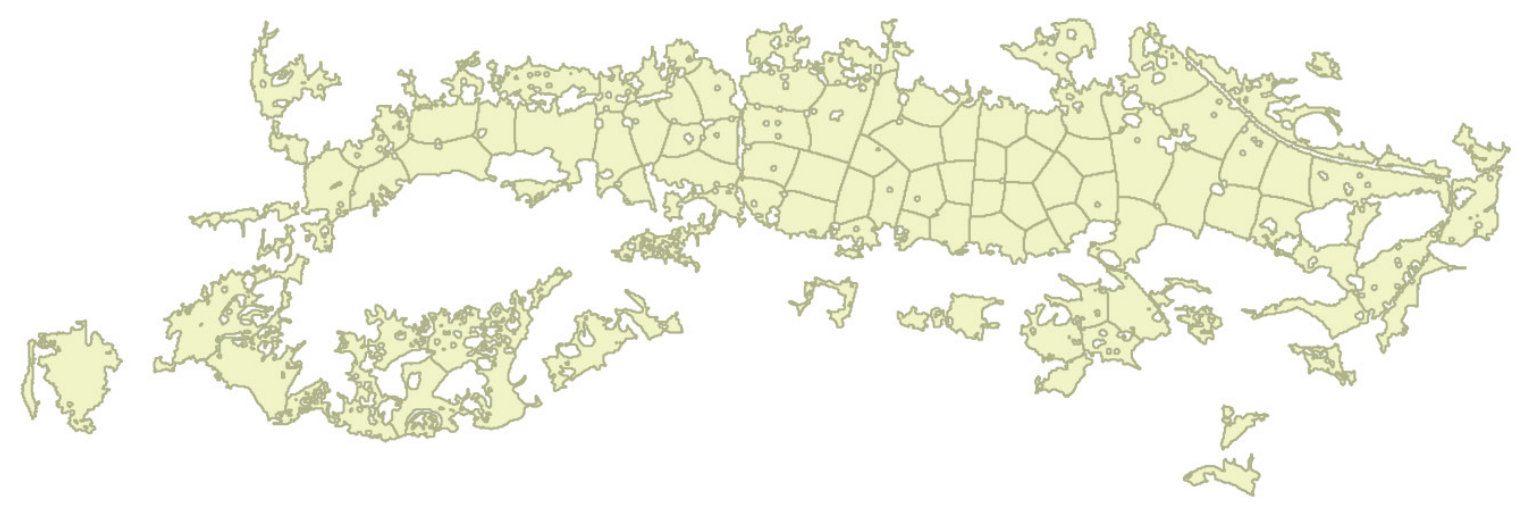

Figure 5. Aggregation of example available land polygon

\subsubsection{Calculating Capacity of Photovoltaic Power Plants}

PV power plants are built using different configurations and spacing, which would affect the power density on a case-by-case basis. The power density value is used to characterize how much capacity can fit within a selected swath of land. Citing previous work by Ong et al. (2013) that explored how much land is needed for siting utility-scale PV plants, we decided on a standard of $32 \mathrm{MW} / \mathrm{km}^{2}$ as our static power density value.

\subsubsection{Technical Potential Results}

Figure 6 outlines the available nameplate capacity for each municipality where capacity is available. Municipalities without any capacity as defined by the assumed exclusions are not listed. Based on our assumptions, 56 of the 78 total municipalities of Puerto Rico are listed with some level of solar capacity. Most of the interior municipalities did not have any capacity because of the geographic exclusions used in this study. The lowest capacity for a PV plant observed in a municipality was $10 \mathrm{MW}$. The maximum capacity within a county was 2,000 MW. 


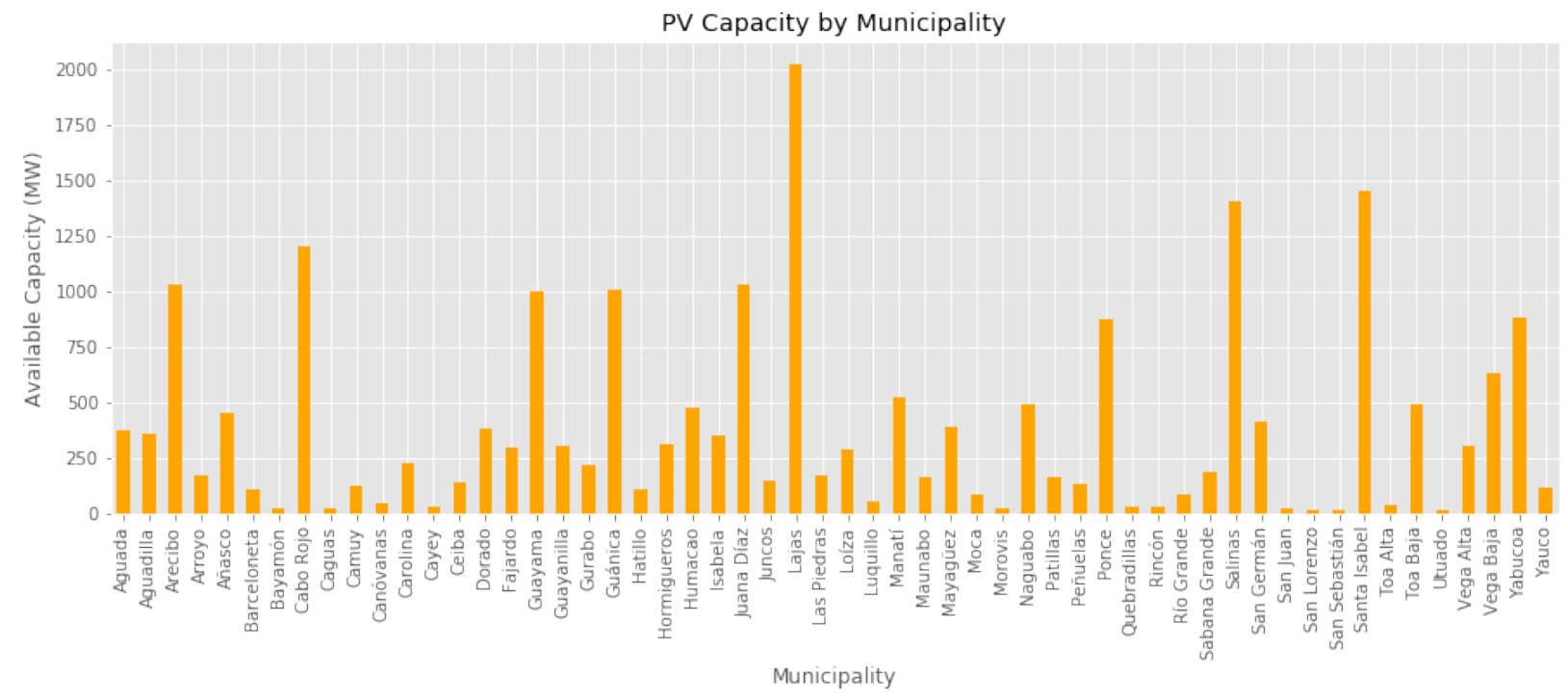

Figure 6. Technical Potential PV capacity for Puerto Rico

Annual potential electricity output is calculated by taking the long-term mean capacity factor for the available land determined from the exclusion layers. The average annual potential output is outlined in Figure 7.

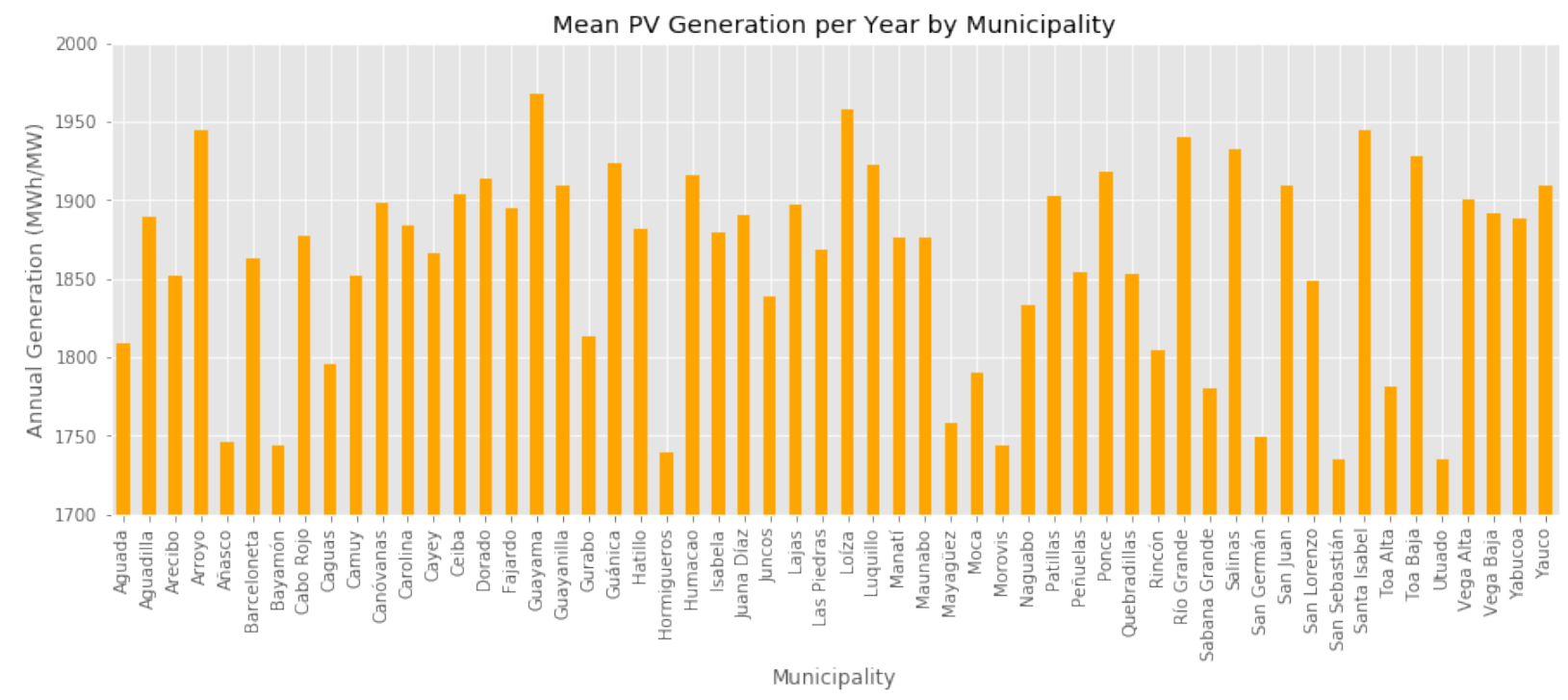

Figure 7. Technical Potential Mean PV generation per year by municipality

\subsection{Supply Curve Analysis}

The supply curve analysis takes the results of the technical potential and quantifies system and transmission costs. The levelized cost of energy (LCOE) is calculated for each theoretical PV plant site, and the levelized cost of transmission is added to the LCOE to produce a total cost estimate for each site. 


\subsubsection{Transmission Line Routing}

When calculating distance for transmission lines, decisions must be made as to which routes offer the greatest benefit and least negative impact to the landscape. Many of the same decisions that assist in siting a new power plant are used when routing transmission lines, such as social value of land, protected areas, urban areas, and other factors. In our analysis, we used a modified set of exclusions based on the exclusions listed in Table 3 .

Spur lines are the new transmission features used for connecting new PV plants to existing transmission infrastructure. Spur lines are incentivized to avoid protected areas and urban areas using a least-cost path methodology. Pixels classified as "open" have a very low cost, whereas protected areas, water bodies, and urban areas are more expensive. The routes of the spur lines are determined by following the path that is cheapest and nearest the three substations. Note that previously existing transmission corridors are cheaper than open land, which causes spur lines to find the nearest previously existing transmission corridors and then follow that corridor to the nearest substation.

\subsubsection{Cost Assumptions}

Costs for site-level development in addition to transmission interconnection (Table 4 and Table 5) are combined to form a total $\mathrm{LCOE}$ in $\$ / \mathrm{MWh}$, which allows for a relative comparison of costs across the island. The cost inputs listed blow are similar to cost assumptions used by recent Integrated Resource Planning analysis conducted for the Puerto Rico Electric Power Authority (PREPA). Some costs are fixed, including upgrades at the substation to incorporate new generation, whereas other costs vary depending on distance to transmission and nameplate capacity of the system. 
Table 4. Site Cost Assumptions

\begin{tabular}{|l|l|l|}
\hline Assumption & Value & Fixed or Variable \\
\hline Capital cost & $\$ 1.6$ million/MW & Variable \\
\hline Fixed operation and maintenance & $\$ 11,850 / \mathrm{MW} / \mathrm{yr}$ & Variable \\
\hline Fixed charge rate & 0.0669 & Fixed \\
\hline
\end{tabular}

Table 5. Transmission Cost Assumptions

\begin{tabular}{|l|l|l|}
\hline Assumption & Value & Fixed or Variable \\
\hline Interconnecting line (gen-tie) & $\$ 1.5$ million/mile & Variable \\
\hline $\begin{array}{l}\text { Right-of-way costs }(115 \mathrm{kV}, 50-\mathrm{ft} . \text { wide) } / \\
\text { land cost }\end{array}$ & $\$ 3 / \mathrm{m}^{2}$ & Variable \\
\hline New bay for interconnection & $\$ 2.4$ million & Fixed \\
\hline Control house extension & $\$ 300,000$ & Fixed \\
\hline
\end{tabular}

\subsubsection{Supply Curve Results}

The results of the supply curve analysis allow for a relative comparison of the cost for integrating new PV capacity into the grid.

As shown in Figure 8, the cheaper total LCOE sites tend to be larger in capacity, which demonstrates the economies of scale for larger plants that generate a greater amount of electricity, which offsets fixed site and transmission costs for each plant. The capacity represented here is far beyond the maximum peak load for the island, and therefore it shows more capacity than would be needed to meet the needs of the island; however, these plots do not consider the economic and market potential for development. In Figure 9, the cumulative capacity assumes that the best locations are developed first, and as build-out occurs, the more marginal locations are built out next. This ignores the complex decision paths for new power plant development, and therefore it is only illustrative. Additional investigation should be conducted to determine the economic and market viability of new developments.

The supply curve analysis results can be used as inputs to capacity expansion and production cost models. 


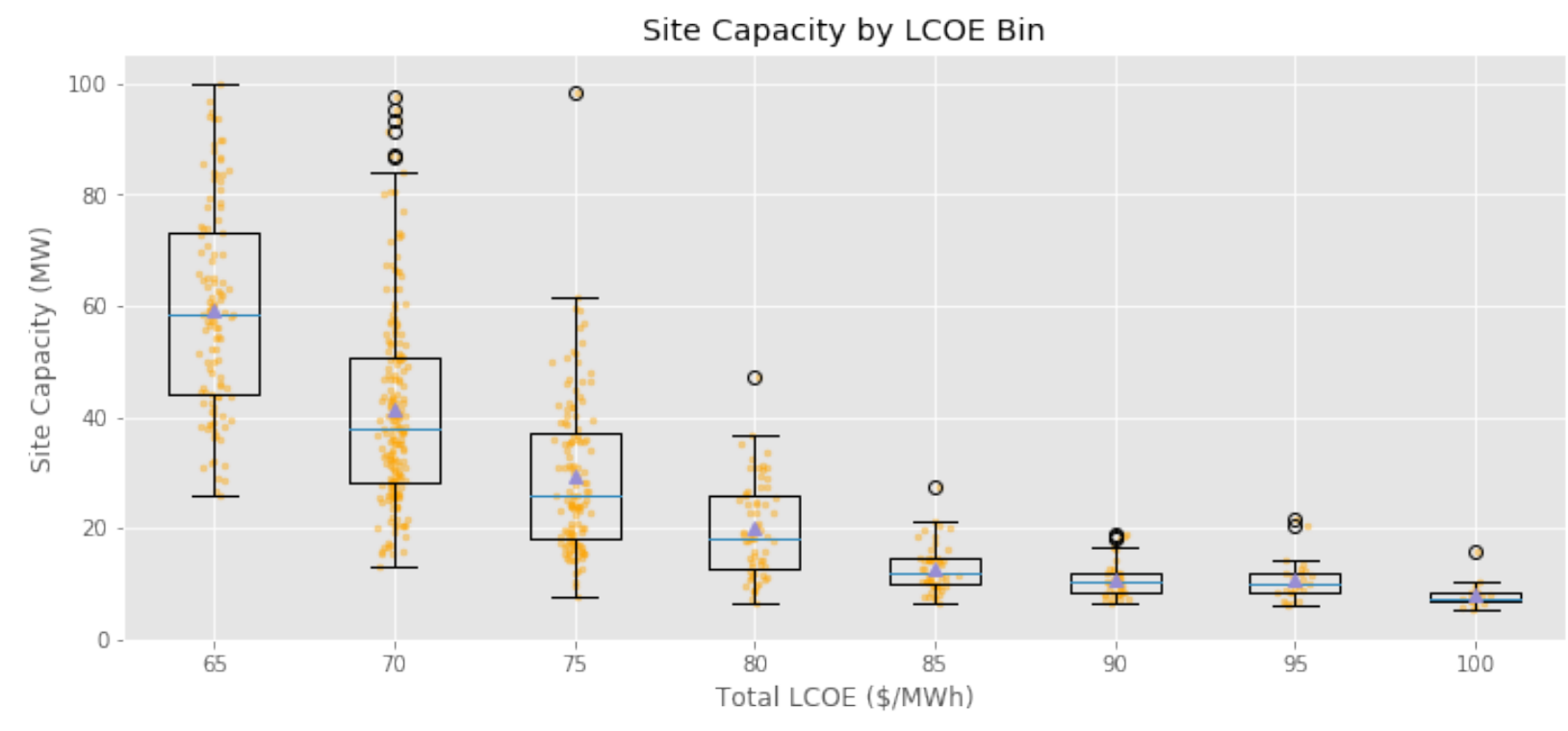

Figure 8. Site capacity by LCOE bin for Puerto Rico

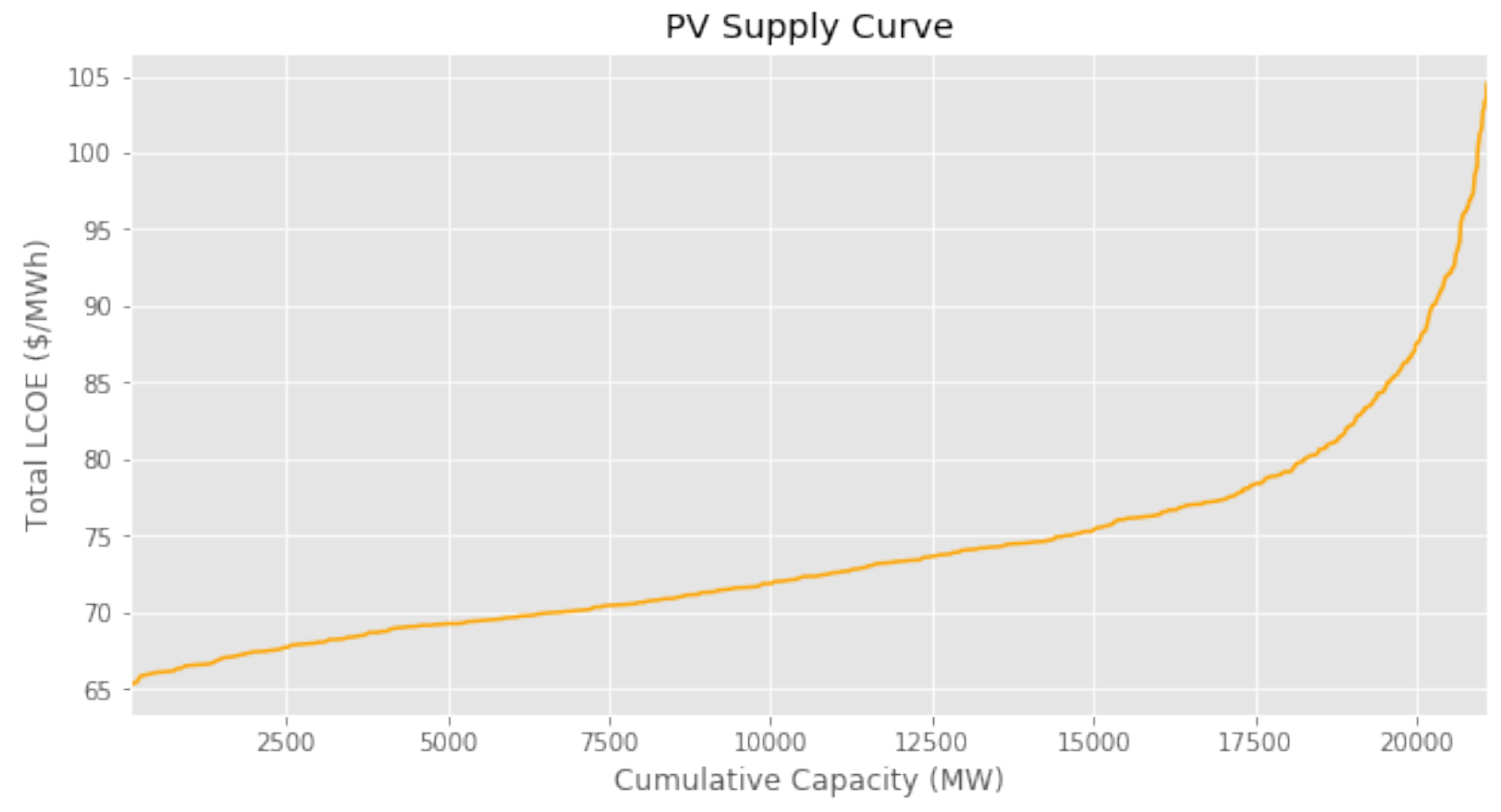

Figure 9. PV supply curve for Puerto Rico 


\section{Interannual Variability}

With the increasing adoption of PV generation in the United States and throughout the world, it will become more important to understand the resource behind this type of generation. Not understanding this resource, or assuming a typical meteorological year for multiple years, could have dire consequences and lead to instability in the grid due to over- or under-estimated annual electricity generation (Lopez et al. 2017; Bryce et al. 2018; Kumler et al. 2018). The following sections illustrate the importance of considering the interannual variability of the solar resource and generation for 1-axis tracking and fixed-tilt setups.

\subsection{General Variability of the Solar Resource}

To understand PV generation variability, it is important to understand the variability driving the generation, or the general climate of Puerto Rico. Figure 10 illustrates the interannual variability of GHI during the year using 20 years of the NSRDB data (1998-2017).

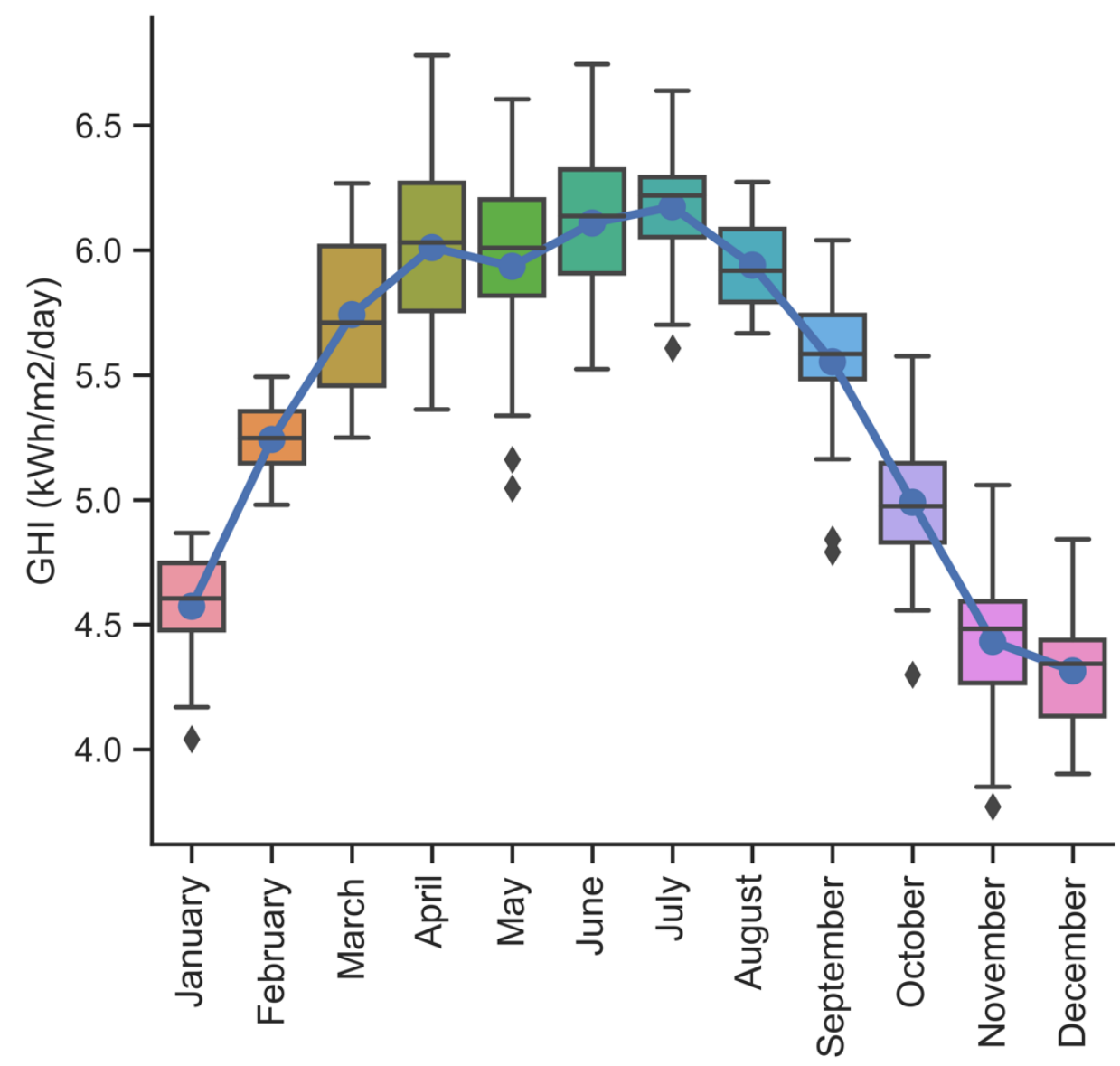

Figure 10. Interannual variability of GHI for Puerto Rico from 1998-2017 shown on the monthly scale. The blue line and dots represent the mean for those months, and the box plot represents the monthly ranges during the 20 years.

As shown in Figure 10, Puerto Rico has a fairly representative solar profile during the entire year, with peak solar radiation occurring during the summer months and minimums during the winter months. The slight plateau during the months from May-August are caused by the wet 
season, which begins in spring and continues through summer (Gómez-Gómez, RodríguezMartínez, and Santiago 2014). This wet season brings increased cloudiness and thus decreased amounts of radiation.

This change is more dramatically shown in Figure 11, which represents DNI. DNI peaks during the winter months, which experiences the least amount of cloudiness, and bottoms out during the wet summer months. The results from figures 10 and 11 are consistent with what we would expect from the climate of Puerto Rico.

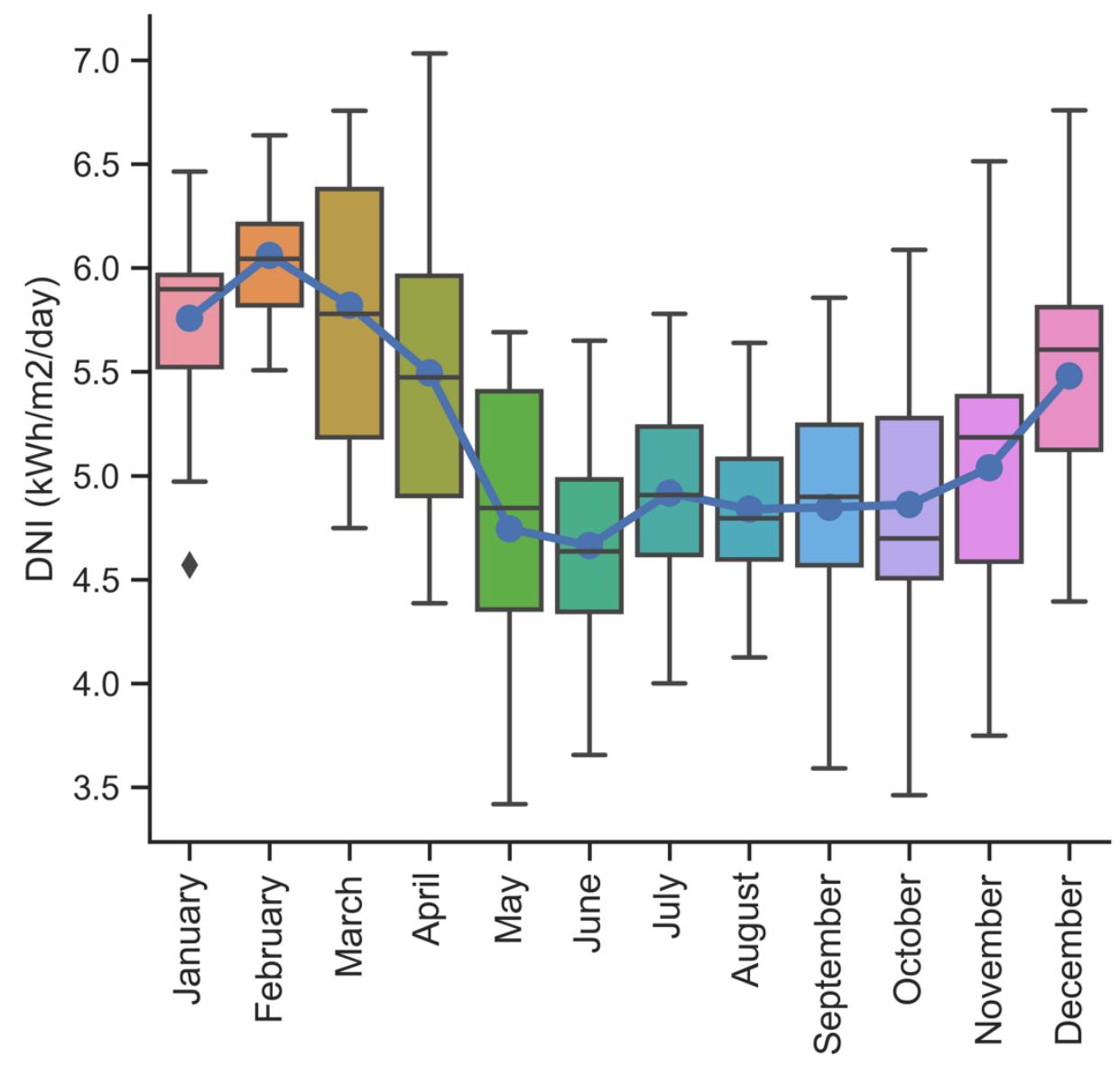

Figure 11. Interannual variability of DNI for Puerto Rico from 1998-2017 shown on the monthly scale. The blue line and dots represent the mean for those months, and the box plot represents the monthly ranges during the 20 years.

To gain a sense of how the solar resource changes on a yearly basis, Figure 12 shows GHI resource variability. Similar to figures 10 and 11 , each box plot is based on monthly averages, with the yearly means shown by the blue line. It is evident that the yearly mean is consistently below the median, meaning that almost every year experiences lower average resource values than illustrated by the median. During the 20 years, both the mean and median can vary up to $10 \%$ across the entire island of Puerto Rico. 


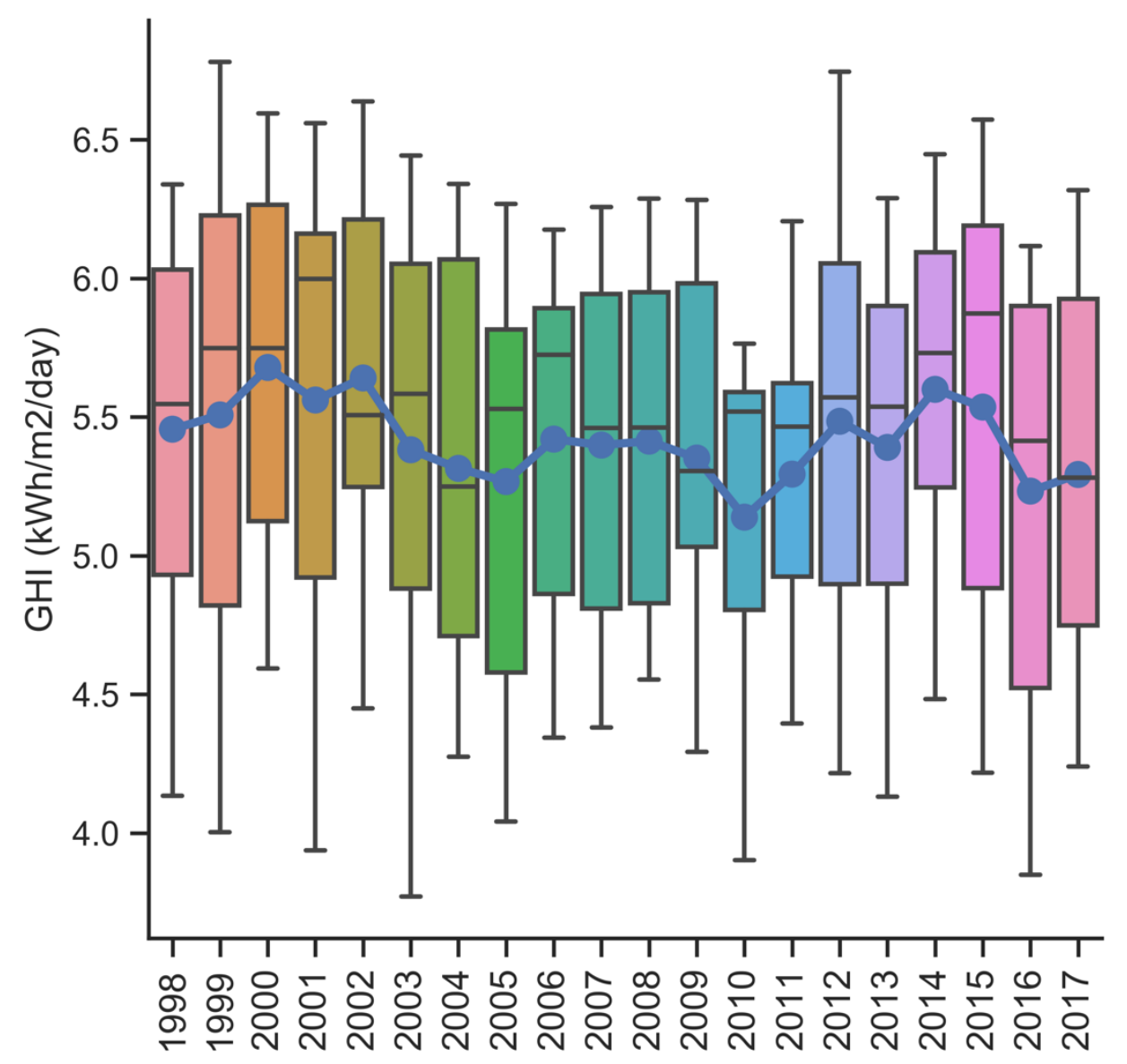

Figure 12. Interannual variability of GHI for Puerto Rico from 1998-2017. The blue line and dots represent the mean for those months, and the box plot represents the monthly ranges during the 20 years.

Although these figures give an idea of how the solar resource behaves across Puerto Rico, they do not provide any context about how the solar resource varies spatially. Figure 13 maps the resource of Puerto Rico and the surrounding islands as a 20-year average. As shown, the average resource over the island is largely a function of the topography, land cover, and thus climate. Average values across Puerto Rico can vary by $25 \%$ or more, with coastal, low-lying areas exhibiting the highest GHI values and more mountainous areas (and those in the island's rain shadow) showing the lowest GHI values. 


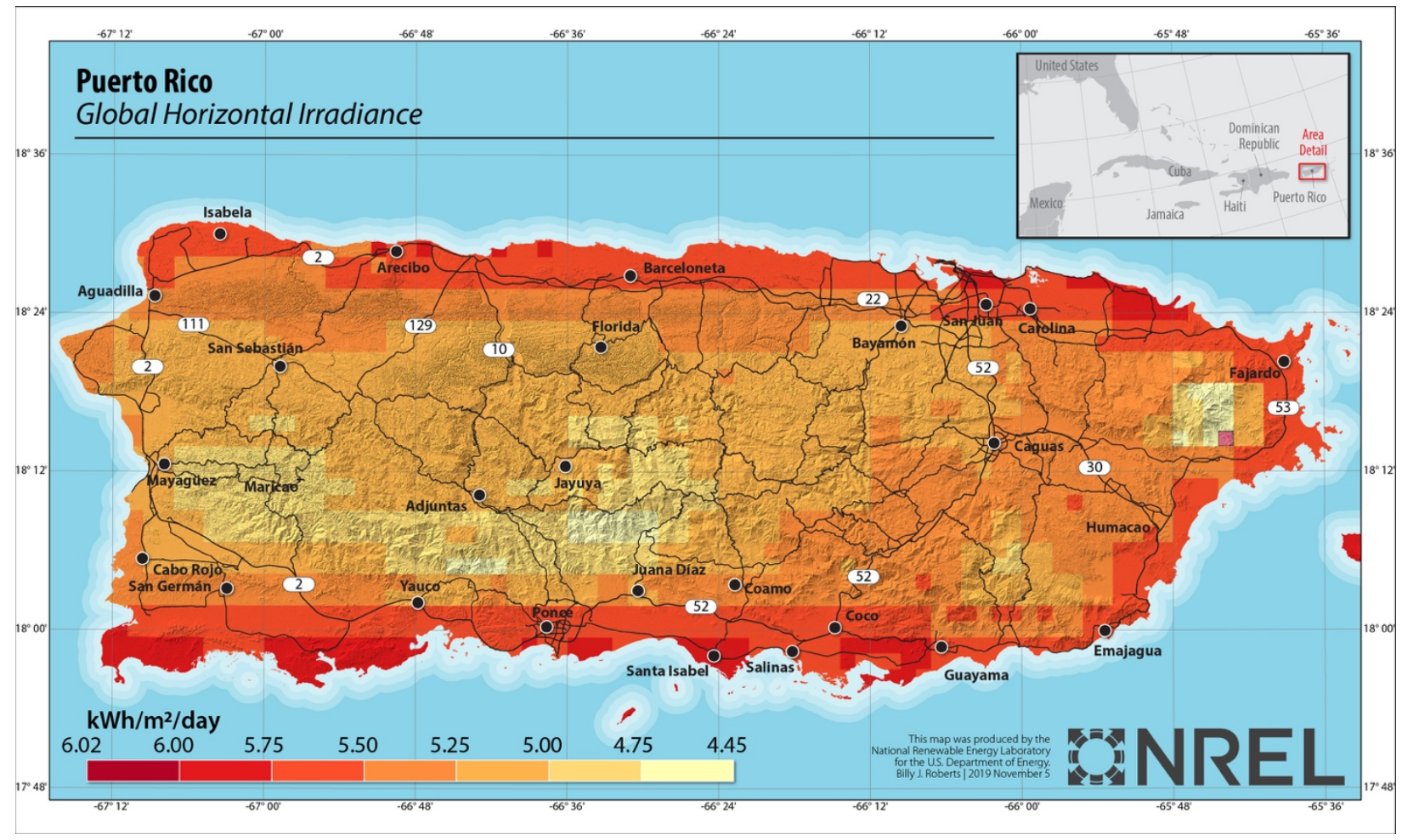

Figure 13. Annual average GHI for Puerto Rico

Figure 14 builds on Figure 13 and shows the coefficient of variation (COV) of GHI. COV is a useful metric for determining how a variable can vary in time, and it is defined as:

$$
\operatorname{COV}=\frac{\sqrt{\frac{\sum_{i=1}^{N}\left(x_{i}-\bar{x}\right)^{2}}{N-1}}}{\bar{x}} * 100 \%
$$

where $\mathrm{x}$ is the yearly mean, and $\bar{x}$ is the multiyear mean. COV is essentially a measure of how the standard deviation varies about the mean. Generally, more variability is seen in mountainous and forested regions, whereas lower variability exists along the coastlines, specifically in the west and south parts of the island. This is consistent with the map of GHI shown in Figure 13, which shows higher resource along the coasts and less resource in the hills/mountains. As a note, the interannual variability observed are consistent with the results obtained by Habte et al. 2020; however, the latter study started from the 30 minute temporal and $4 \mathrm{~km} \mathrm{x} 4 \mathrm{~km}$ spatial resolution of the NSRDB to calculate COV. These spatial patterns also align with what we would expect from Puerto Rico's climate: typical northeasterly trade winds cause the north/northeast part of the island to have higher annual rainfall (and thus clouds), creating a rain shadow for the south/southwest. The south/southwest part of Puerto Rico shows the highest average GHI and lowest variability. 


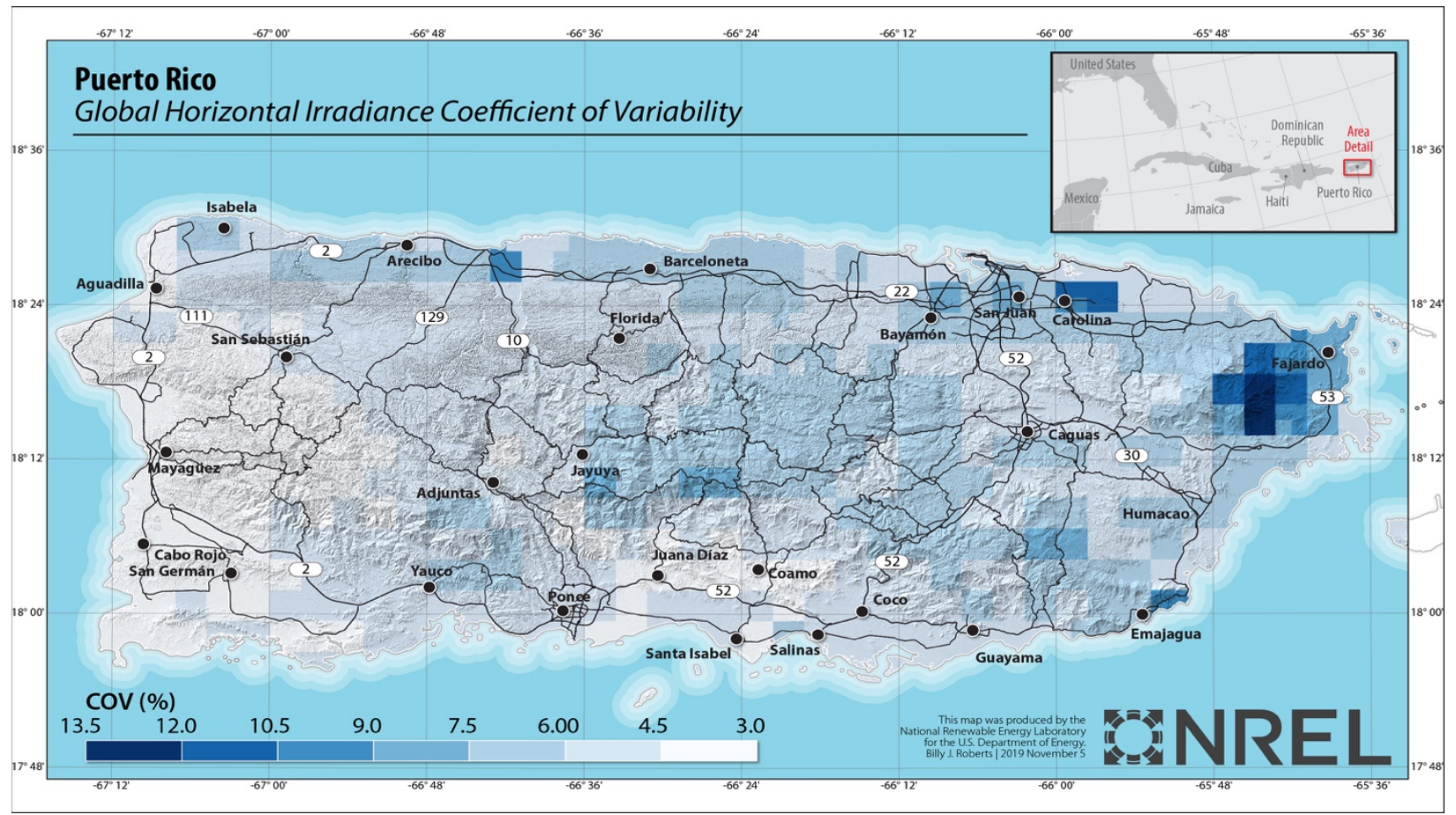

Figure 14. Variability of GHI in terms of COV. Generally, there is more variability in the mountainous interior and more forested areas.

\subsection{General Variability of the Solar Generation}

PV generation for Puerto Rico follows a similar trend to resource variability for both fixed-tilt and 1-axis tracking setups (Figure 15(a) and (b)), but to varying degrees. For fixed-tilt, generation varies by roughly $5 \%$ from one year to another, with typical annual generation values in the range of 1,500-1,600 MWh. One-axis generation exhibits greater annual resource, which is expected, but also greater interquartile range (the middle $50 \%$ of the distribution) and more drastic outliers. The outliers in these plots, which are only lower extremes, exist in areas or pixels where the resource is generally low and highly variable, such as El Yunque National Forest in the northwest part of the island. Although in reality this area would not be developed for PV production, it is important to show the entire possible variability across Puerto Rico. 

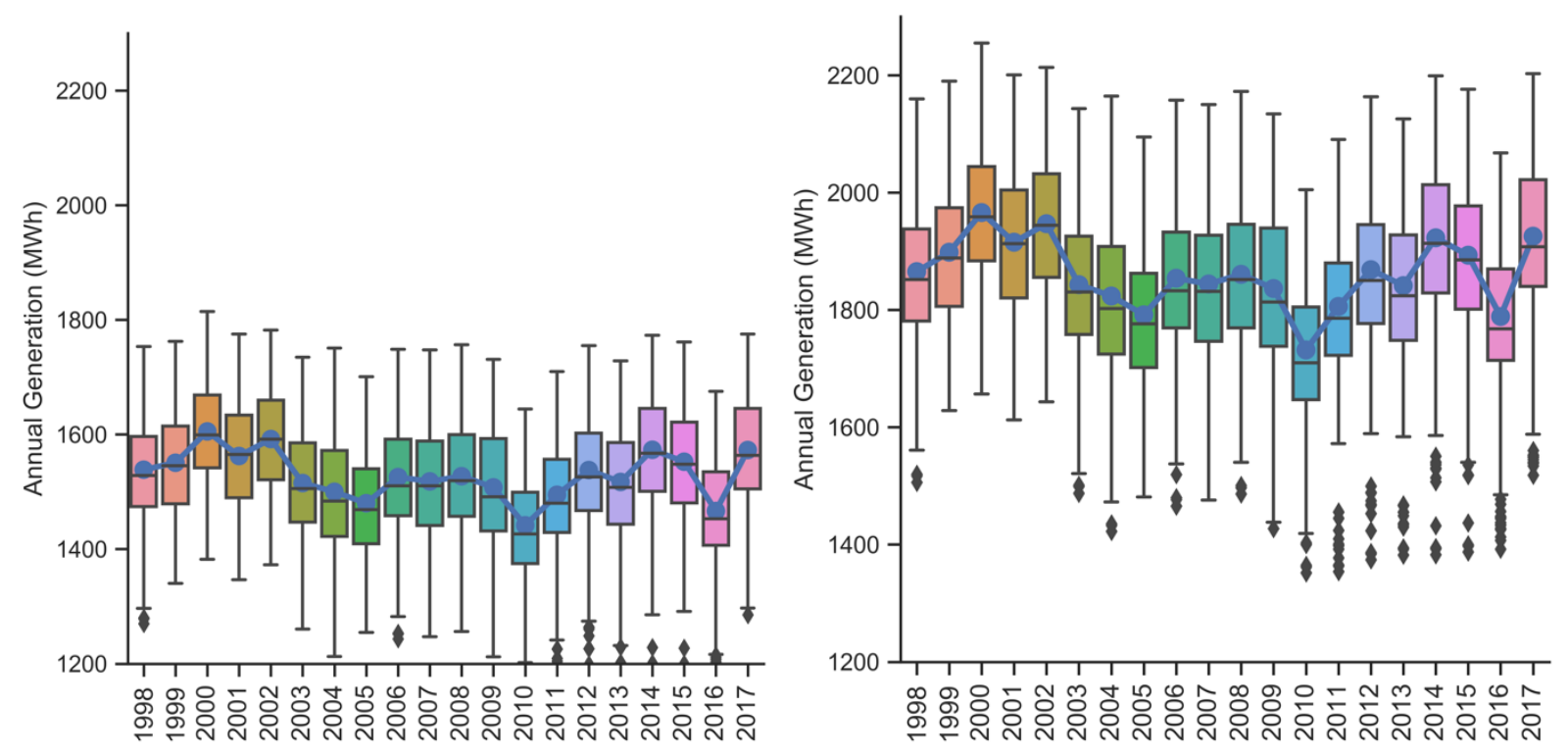

Figure 15. Interannual variability of (a) fixed-tilt solar generation and (b) 1-axis solar generation. Box plots are based on monthly averages for each pixel.

Another way to visualize the variability of the PV generation is to calculate exceedance probabilities. Exceedance probabilities show the probability (e.g., 10\%, 50\%, 90\%) of generation exceeding a value for a given year, which is dependent on each cell (Lopez et al. 2017). For example, a P10 exceedance probability means that solar generation (in this case) exceeded in $10 \%$ of years. This metric provides a useful way to spatially visualize interannual variability in terms of probability of solar energy generated. Figures 16, 17, and 18 illustrate the P10, P50, and P90 of the fixed-tilt and 1-axis tracking setups for Puerto Rico. 


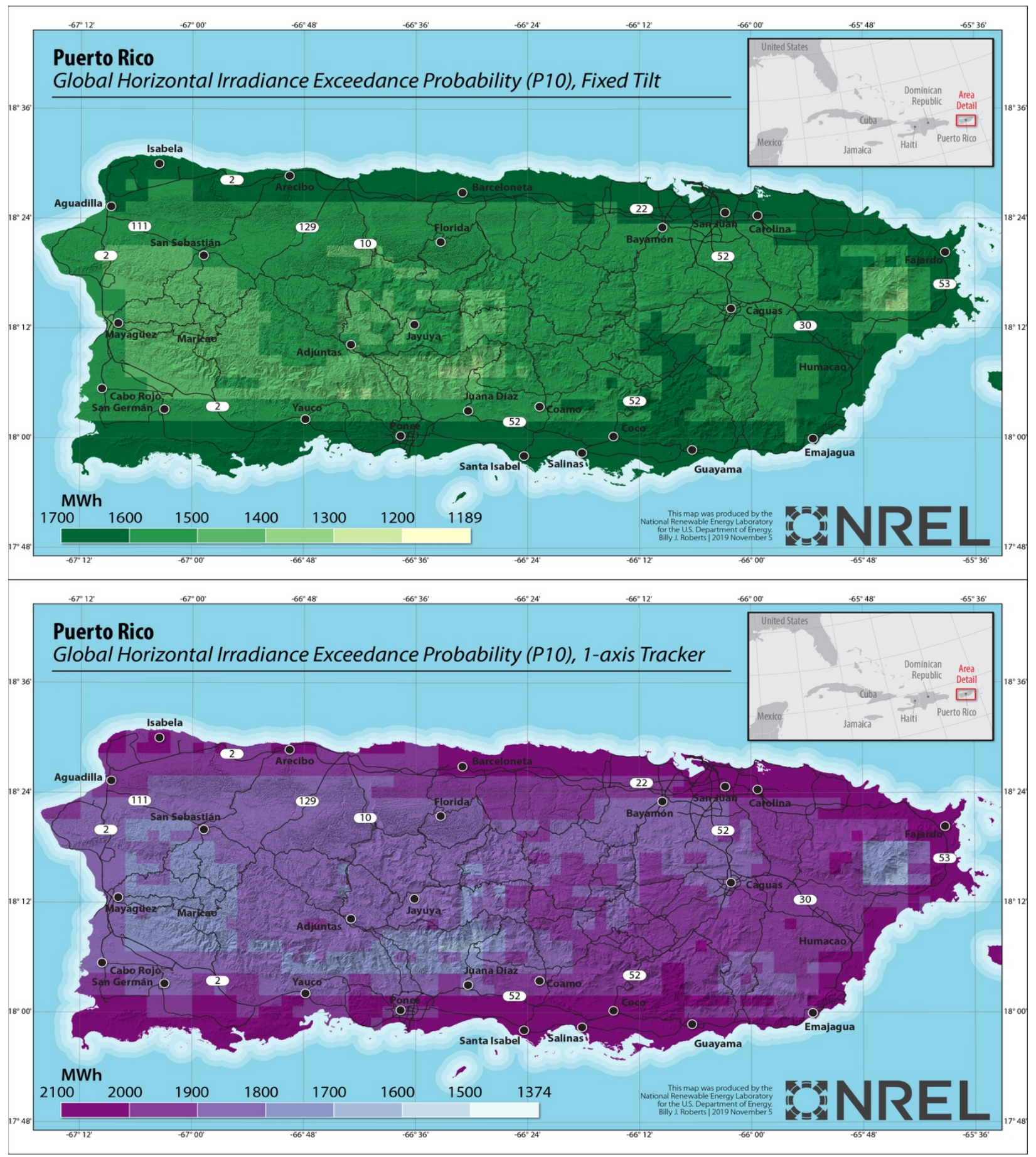

Figure 16. P10 exceedance probabilities for fixed-tilt (top) and 1-axis (bottom) tracking setups 


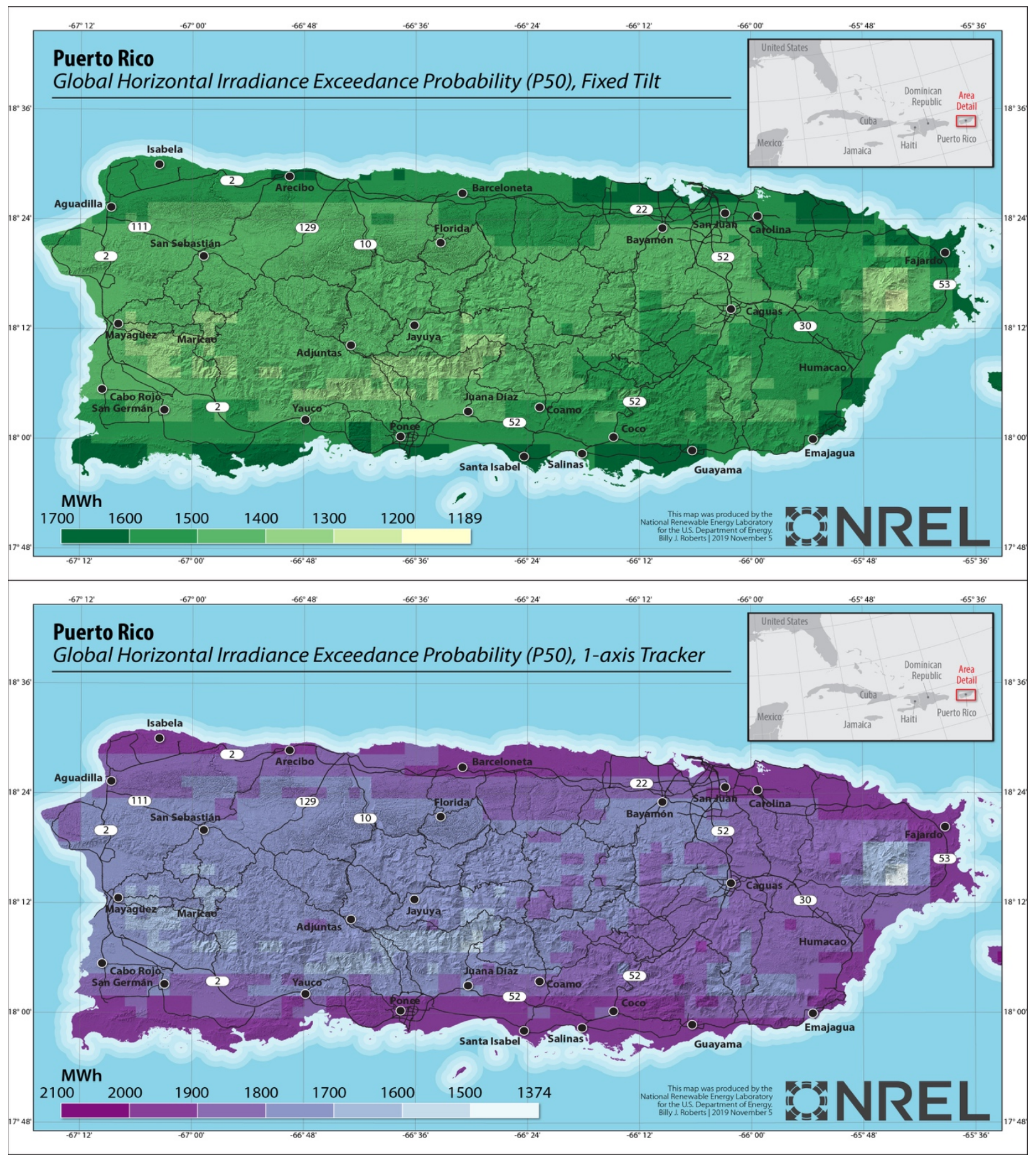

Figure 17. P50 exceedance probabilities for fixed-tilt (top) and 1-axis (bottom) tracking setups 


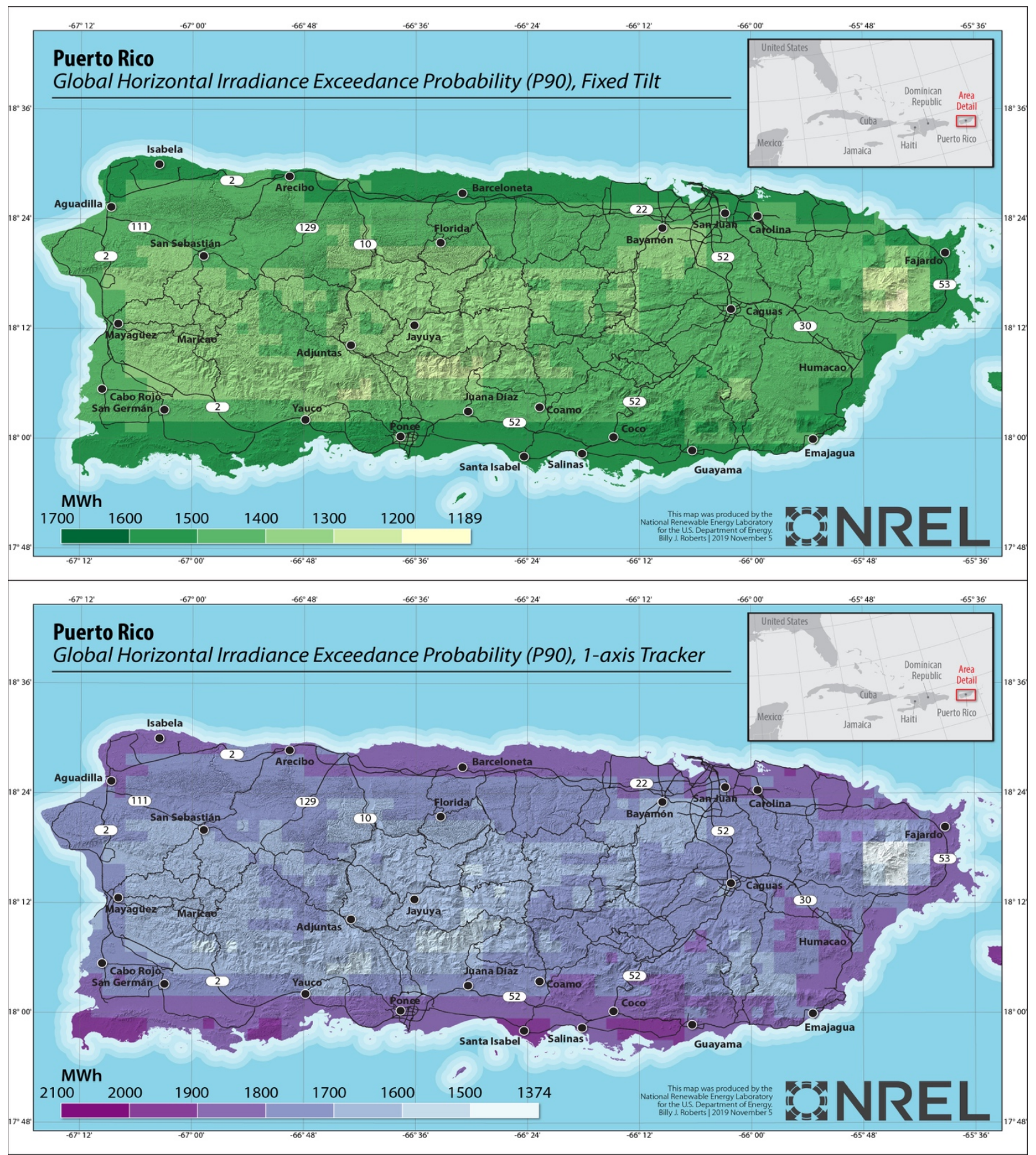

Figure 18. P90 exceedance probabilities for fixed-tilt (top) and 1-axis (bottom) tracking setups

A closer look at figures 16-18 shows a clear trend. As the exceedance probability increases, the value of the GHI needed to exceed this threshold decreases. This is shown both for the fixed-tilt and 1-axis tracking PV setups. As expected, the exceedance probabilities for 1-axis tracking are higher than those for the fixed-tilt tracking because 1-axis tracking generally generates more electricity and thus its exceedance probability thresholds are higher. 
The spatial patterns in the exceedance probability maps are consistent with the general resource across the island. Along the coast (especially in the south), higher GHI values are shown, with lower values in the mountainous interior and more forested areas. These higher GHI values also coincide with most of the developable area for PV installation shown in Figure 3. To even greater benefit, these coastal areas exhibit the lowest COV values, shown in Figure 14.

\subsection{General Variability of the Levelized Cost of Energy}

Another way to assess the interannual variability of solar energy for Puerto Rico is to estimate the cost of generating electricity for various PV setups. A commonly used metric, the LCOE, attempts to consider various factors driving the cost of energy, such as capital costs, operationand-maintenance costs, and fuel costs. This makes comparing various types of energy production easier, albeit not completely "one-to-one." In Figures 19 and 20, LCOE is calculated for both fixed-tilt and 1-axis PV setups, and the interannual variability is shown with the respective capacity factors. In addition, Table 6 shows the costs/numbers used in the LCOE calculation. These costs include capital and fixed operation-and-maintenance costs, which describe the costs needed to finance and operate/maintain PV plants, usually described in units of $\$ / M W$ or $\$ / \mathrm{MW} / \mathrm{yr}$. 

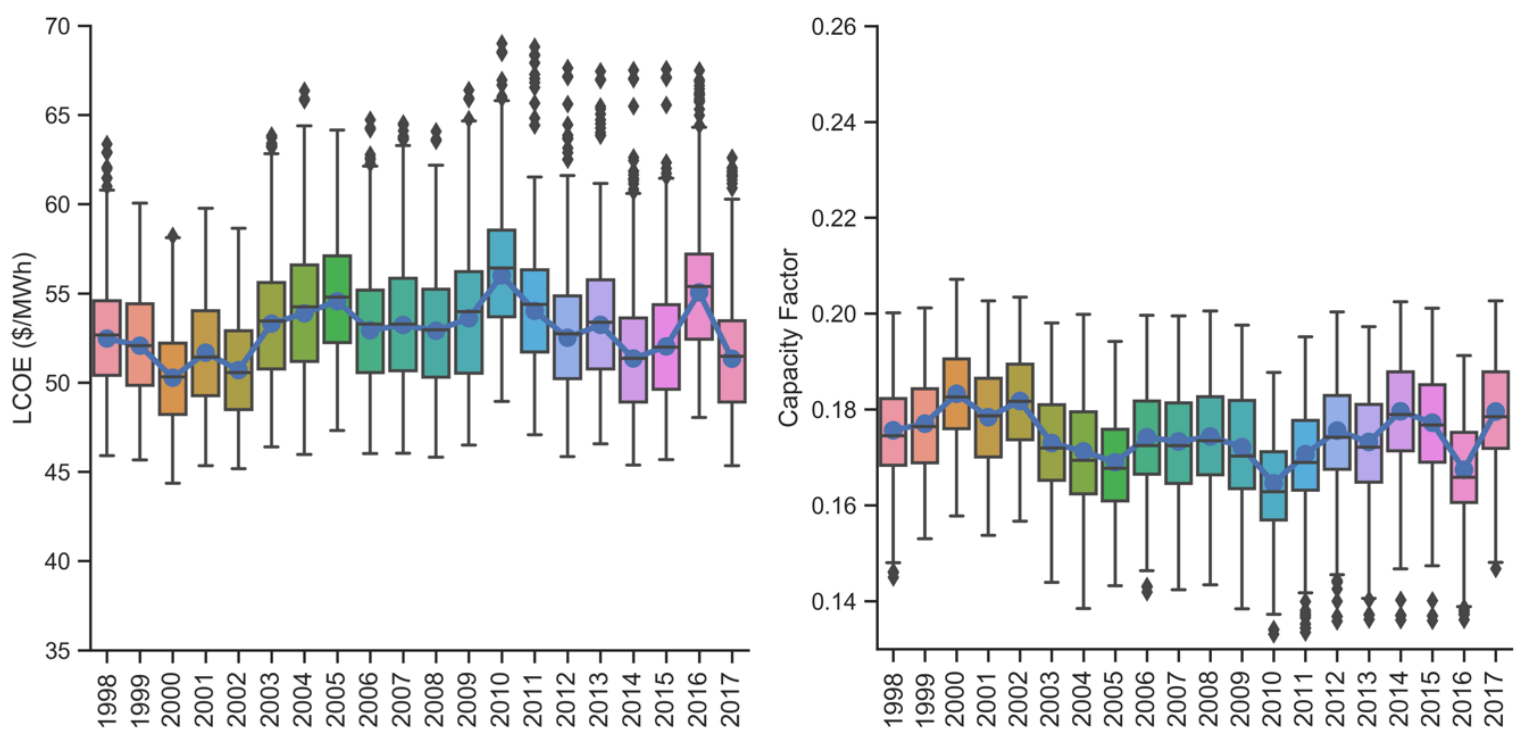

Figure 19. Interannual variability of LCOE for fixed-tilt PV setups (a) and respective capacity factors (b)
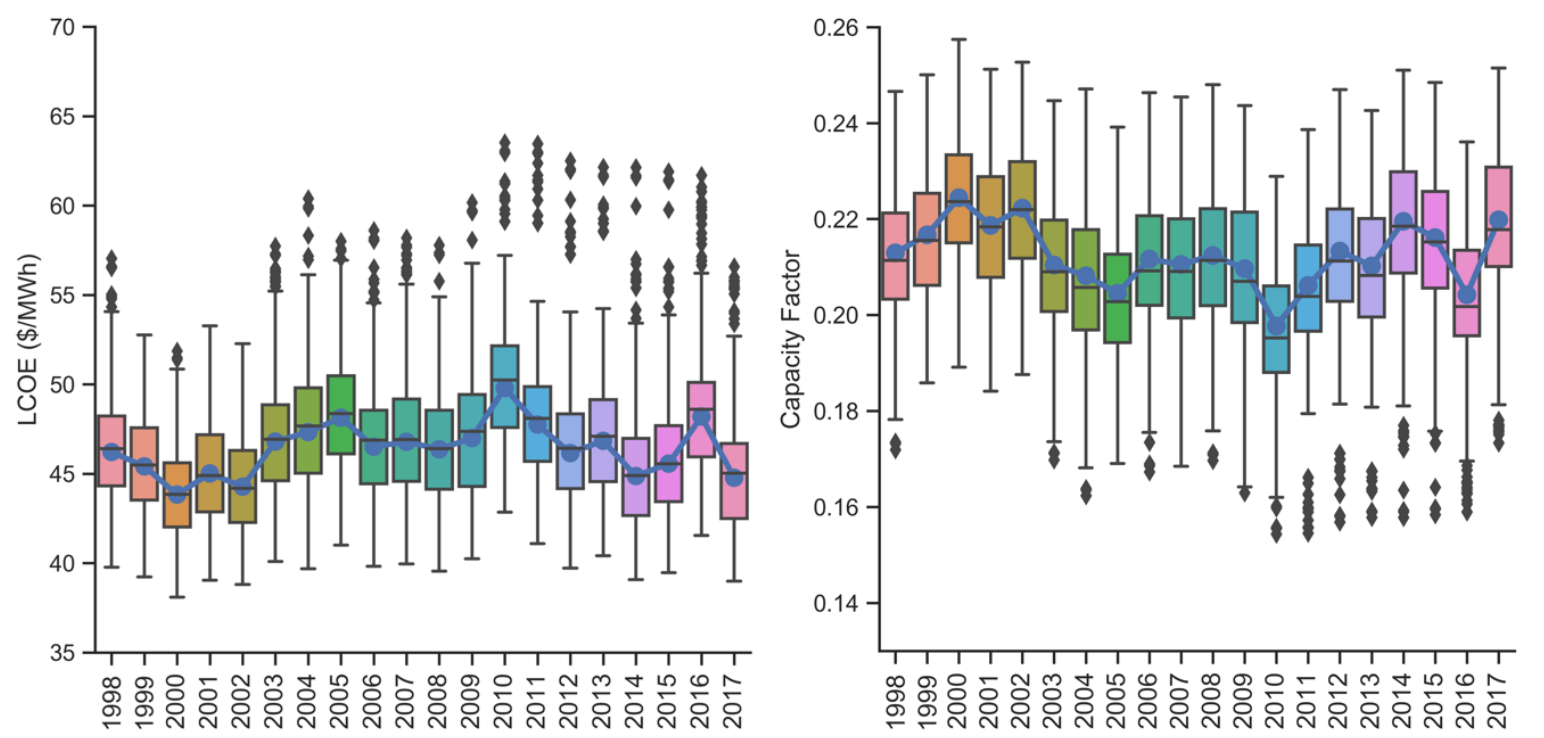

Figure 20. Interannual variability of LCOE for 1-axis tracking setups (a) and respective capacity factors (b)

Table 6. Associated Costs (Capital and Fixed Operation-and-Maintenance) for Fixed-Tilt and 1-Axis Tracking PV Setups in Relation to the LCOE Calculation

\begin{tabular}{|l|l|l|}
\hline & Capital Costs & FOM Costs \\
\hline Fixed-tilt & $\$ 1,066,127 / \mathrm{MW}$ & $\$ 9,100 / \mathrm{MW} / \mathrm{yr}$ \\
\hline 1 -axis & $\$ 1,127,694 / \mathrm{MW}$ & $\$ 10,400 / \mathrm{MW} / \mathrm{yr}$ \\
\hline
\end{tabular}

Comparing Figure 19 to Figure 20 shows, on average, that 1-axis tracking appears to be more cost-effective, with an average LCOE of \$5/MWh less than the fixed tilt. This is not surprising because 1-axis tracking setups generally generate more electricity than fixed-tilt setups despite the additional capital costs and operational costs associated with 1-axis tracking. 


\section{Conclusion}

This report described the process for developing solar time-series data for quantifying the solar resource in Puerto Rico and the U.S. Virgin Islands. Using these data, a technical potential and supply curve analysis attempted to characterize the available land and the cost for development given prior assumptions. The benefit of using time-series solar resource data is that the intra- and interannual variability of the solar resource can be characterized and provide a better understanding of the bounds of the solar generation given 20-year historical data. The data and insights produced from this analysis can be used as inputs into capacity expansion and production cost models and for determining locations to further investigate for new utility-scale solar development. 


\section{References}

Blair, N., N. DiOrio, J. Freeman, P. Gilman, S. Janzou, T. Neises, and M. Wagner. 2017. System Advisor Model (SAM) General Description (Version 2017.9.5) (NREL/TP-6A20-70414).

Golden, CO: National Renewable Energy Laboratory. https://doi.org/10.2172/1440404.

Brown, A., P. Beiter, D. Heimiller, C. Davidson, P. Denholm, J. Melius, A. Lopez, D. Hettinger, M. David, and G. Porro. 2016. Estimating Renewable Energy Economic Potential in the United States: Methodology and Initial Results (NREL/TP-6A20-64503). Golden, CO: National Renewable Energy Laboratory. https://doi.org/10.2172/1215323.

Bryce, R., I. L. Carreño, A. Kumler, B. M. Hodge, B. Roberts, and C. B. Martinez-Anido. 2018. "Consequences of Neglecting the Interannual Variability of the Solar Resource: A Case Study of Photovoltaic Power Among the Hawaiian Islands.” Solar Energy 167: 61-75.

Buster, G., M. Rossol, G. Maclaurin, Y. Xie, and M. Sengupta. 2021. “A Physical Downscaling Algorithm for the Generation of High-Resolution Spatiotemporal Solar Irradiance Data." Solar Energy 216: 508-17.

Gómez-Gómez, F., J. Rodríguez-Martínez, and M. Santiago. 2014. Hydrogeology of Puerto Rico and the outlying islands of Vieques, Culebra, and Mona. Washington, D.C.: U.S. Department of the Interior, U.S. Geological Survey. https://doi.org/10.3133/sim3296.

Habte, A., M. Sengupta, C. Gueymard, A. Golnas, and Y. Xie. 2020. "Long-term spatial and temporal solar resource variability over America using the NSRDB version 3 (1998-2017)." Renewable and Sustainable Energy Reviews 134. https://doi.org/10.1016/j.rser.2020.110285.

Kumler, A., I. L. Carreño, M. Craig, B. M. Hodge, W. Cole, and C. Brancucci. 2018. "Interannual Variability of Wind and Solar Electricity Generation and Capacity Values in Texas." Environmental Research Letters.

Lopez, A., B. Roberts, D. Heimiller, N. Blair, and G. Porro. 2012. U.S. Renewable Energy Technical Potentials: A GIS-Based Analysis (NREL/TP-6A20-51946). Golden, CO: National Renewable Energy Laboratory. https://www.nrel.gov/docs/fy12osti/51946.pdf.

Lopez, A., G. Maclaurin, B. Roberts, and E. Rosenlieb. 2017. Capturing Inter-Annual Variability of PV Energy Production in South Asia (NREL/TP-6A20-68955). Golden, CO: National Renewable Energy Laboratory.

Ong, S., C. Campbell, P. Denholm, R. Margolis, and G. Heath. 2013. Land-Use Requirements for Solar Power Plants in the United States (NREL/TP-6A20-56290). Golden, CO: National Renewable Energy Laboratory. https://doi.org/10.2172/1086349.

Sengupta, M., Y. Xie, A. Lopez, A. Habte, G. Maclaurin, and J. Shelby. 2018. "The National Solar Radiation Data Base (NSRDB)." Renewable and Sustainable Energy Reviews 89: 51-60. https://doi.org/10.1016/j.rser.2018.03.003. 